\title{
Early Paleozoic Extension-Compression Transition and Formation of a Paleo-Oil Reservoir System in the NW Sichuan Basin: Implications for Deeply Buried Hydrocarbon Accumulation
}

\author{
Xiao Liang $\mathbb{D},{ }^{1,2}$ Shu-gen Liu $\mathbb{D},{ }^{1,3}$ Liang-liang Wu $\mathbb{D},{ }^{4}$ Bin Deng $\mathbb{D}^{1},{ }^{1}$ Jing Li $\mathbb{D},{ }^{2}$ \\ Meng-lin Zhang $\left({ }^{2},{ }^{2}\right.$ and Xu-hang Tan $\left(^{2}\right.$ \\ ${ }^{1}$ State Key Laboratory of Oil and Gas Reservoir Geology and Exploitation, Chengdu University of Technology, Chengdu, \\ Sichuan 610059, China \\ ${ }^{2}$ CNPC Chuanqing Drilling Engineering, Chengdu, Sichuan 610051, China \\ ${ }^{3}$ Xihua University, Chengdu, 610039 Sichuan, China \\ ${ }^{4}$ State Key Laboratory of Organic Geochemistry, Guangzhou Institute of Geochemistry, Chinese Academy of Science, Guangzhou, \\ Guangdong 510640, China
}

Correspondence should be addressed to Shu-gen Liu; lsg@cdut.edu.cn

Received 6 January 2021; Revised 3 March 2021; Accepted 21 April 2021; Published 27 May 2021

Academic Editor: Kun Zhang

Copyright (C) 2021 Xiao Liang et al. This is an open access article distributed under the Creative Commons Attribution License, which permits unrestricted use, distribution, and reproduction in any medium, provided the original work is properly cited.

\begin{abstract}
Owing to multiple tectonic events after the Late Triassic, the northern segment of the western Sichuan depression (NSWSCD) has a complex geological history of significant uplift and deeply buried. With abundant oil and gas play in the NSWSCD, the study of paleo-oil reservoir systems and early hydrocarbon accumulation in this area is of great significance for deep marine hydrocarbon distribution prediction in complex structural settings. Analysis on the northern section of the MianyangChangning Intracratonic Sag (MY-CN IS) and the Tianjingshan Paleouplift (TJS PU), the two Early Paleozoic tectonic units are laterally superimposed. Combined the reservoir bitumen of the Sinian Dengying Fm firstly, the biomarker $\left(\mathrm{TT}_{23} / \mathrm{tT}_{24}, \mathrm{~S}_{21} / \mathrm{S}_{22}\right.$, etc.) and Organic $\delta^{13} \mathrm{C}$ (lighter than $30 \%$ ) characteristics indicate that the Sinian-Jurassic paleo-oil system in the TJS PU area is the main source of Lower Cambrian organic-rich black shale. This is closely related to the superimposition and combination effects of the intracratonic sag and paleouplift. Therefore, this study establishes a geological-geochemical accumulation model through a combination of $R_{o}$ and fluid inclusion data. The No. 1 fault is an important zoning fault in the NSWSCD, which significantly controls the division of the oil-gas zone. The process of paleo-oil reservoir destroyed directly only exists in the frontal deformation zone. The deep marine strata of the eastern No. 1 fault demonstrate the four-center hydrocarbon accumulation processes, which include oil generation, gas generation, gas storage, and gas preservation. The superdeep Dengying Fm has long-term exploration potential in the NSWSCD.
\end{abstract}

\section{Introduction}

Typical dual thrust belt and foreland basin structures are well developed in the western Sichuan Basin [1]. The western Sichuan depression (WSCD) is a foreland depression that has been influenced by Indosinian, Yanshan, and Himalayan tectonic events. Since the Indosinian Orogeny, the typical multistage basin evolution and tectonic movement characteristics in the WSCD have been largely controlled by the formation and evolution of the Longmenshan Thrust Belt
(LMS TB) on the western margin $[2,3]$. Both of these are relatively consistent in the present tectonic pattern $[4,5]$. With the complex tectonic-sedimentary evolutionary process, researches concentrated on the unconformities between continental strata, lithofacies records, and paleo-structural proceeding the Late Triassic $[6,7]$.

The northern segment of the western Sichuan depression (NSWSCD) has one of the longest histories of oil and gas exploration in the Sichuan Basin $[8,9]$. Among the petroleum geological features, there are abundant oil and gas that 
play in the Tianjingshan area. In addition, the discovery of a sizeable Anyue gas field in the middle of the Sichuan Basin and the development of the Early Cambrian MianyangChangning Intracratonic Sag (MY-CN IS) also indicate advantageous exploration prospects for deeply buried marine hydrocarbon in the WSCD $[10,11]$. However, the oil and gas exploration of the deeply buried Dengying and Qixia formation has become increasingly difficult nowadays [12]. Preliminary research indicates that the widespread distribution of the paleo-oil reservoir system in the NSWSCD closely relates to the formation and evolution of the MY-CN IS and the Tianjingshan Paleouplift (TJS PU) in the Early Paleozoic. The prediction of deep hydrocarbon accumulation under the suddenly deformed basin-mountain system of the NSWSCD should also be relevant to paleo-oil reservoirs and deepsuperdeep gas reservoirs in the frontal-deformation zone and depression areas. Therefore, the paltry amount of data available on tectonic-sedimentary processes between the LateSinian and the Early-Triassic highlights the lack of research on the geology of the deep petroleum system.

This study covers a detailed description of tectonicsedimentary evolution during the Early Paleozoic in the NSWSCD. The sources of the paleo-oil reservoirs (oil seeps/bitumens) from the Sinian-Jurassic strata in the TJS PU area were assessed. Additionally, related studies on oil-source correlation, thermal burial history, and deep hydrocarbon accumulation processes were considered. This allows for a better understanding of the extension-compression transition and the processes responsible for the formation of the paleo-oil reservoir system in the northwestern Sichuan Basin. Furthermore, the oil-gas migration model and implications for deeply buried hydrocarbon predictions were clarified.

\section{Geological Setting}

2.1. Stratigraphy, Palaeogeography, and Age Constraints. Owing to the differences in tectonic background and deformation stage, level, and strength, the LMS TB has typical segmentation characteristics of the southern, middle, and northern sections. The structural deformation of the WSCD also shows a certain trend of segmentation characteristics. Combined with oil and gas exploration, the WSCD is divided into southern, middle, and northern segments $[13,14]$. The $150 \mathrm{~km}$ long and $50 \mathrm{~km}$ wide northern segment of the western Sichuan depression (NSWSCD) stretches from Jiangyou-Tongkou in the south to Guangyuan in the north (Figure 1). The development of the LMS TB and the WSCD influences the marine strata that are generally buried at depths that exceed $7000 \mathrm{~m}$. Given the relative ancient geological age ( $>250 \mathrm{Ma}$ ), this study determines that the deeply buried marine strata were deposited from the Late Sinian, after the initial formation of the cratonic basin, to the MiddleLate Triassic that occurred before the evolution of the intracontinental foreland basin (Figure 2).

The Sichuan Basin had a complex tectonic history of supercontinental and multistage extensional events in the Late Proterozoic (pre-Late Sinian) before the construction of the craton. The amalgamated North China Block (NCB) and the Yangtze and Cathaysia blocks (South China Block,
SCB) were a part of the Rodinia supercontinent during the Late Mesoproterozoic and Early Neoproterozoic (1.0$0.8 \mathrm{Ga}$, Figure $1(\mathrm{a}))$. The SCB was separated gradually from Rodinia during the Late Neoproterozoic (830-720 Ma) through oceanic crust subduction [15-17] and related superplume events $[18,19]$. The evidence of superplume events includes a large number of outcrops of Upper Proterozoic basic-ultrabasic intrusions, pyroliths, and metamorphic complexes on the western margin of the SCB. The multistage process of extension and compression in the SCB is named the Xingkai taphrogenesis and is associated with the breakup of the Rodinia supercontinent $[10,20]$.

The Xingkai taphrogenesis started in the Middle-Late Proterozoic. The western margin of the Yangtze Plate exhibits typical rift-derived characteristics, with a set of 803 $\pm 12 \mathrm{Ma}$ continental volcanic rocks (the Suxiong Fm), continental conglomerates, and sandstones that were assigned to the Nanhua Kaijianqiao, Lieguliu, Chengjiang, and Luliang formations [21, 22]. Tectonic tension was sustained up to the Early Sinian. When the climate began to warm-up after the Nanhuan glacial period, the Yangtze block entered a depositional stage. The deposition of black mudstones and the rapid transgression of the Yangtze Craton formed the Doushantuo Fm $\left(\mathrm{Zn}_{2} d s\right)$ and the clasolite and carbonatite marine sequences $[23,24]$. The development of an overlying carbonate platform sequence and fine silica-carbon clasolite led to the deposition of the Dengying Fm $\left(\mathrm{Zn}_{2} d n\right)$, which completely shaped the Sichuan Craton before the Late Sinian [25]. The Upper Sinian Dengying Formation in the Upper Yangtze area has a preserved thickness of $600-1000 \mathrm{~m}$ and can be divided into four categories on the basis of lithology, structure, and the abundance of cyanobacteria [26].

Paraconformities developed between the second $\left(\mathrm{Zn}_{2} d n^{2}\right)$ and the third $\left(\mathrm{Zn}_{2} d n^{3}\right)$ members of the Dengying Fm and Lower Cambrian-Dengying Fm during the Tongwan I and II episodes. Paleogeographic differentiation began to occur in the Upper Yangtze and surrounding areas during the depositional period of the $\mathrm{Zn}_{2} d n^{2}-\mathrm{Zn}_{2} d n^{3}$ [27]. The thickness of $\mathrm{Zn}_{2} d n^{3}$ is inconsistent in the NSWSCD. The black shale has only been preserved in certain areas, and pebbly sandstones dominate the Hujiaba section in Ningqiang. Whether or not the WSCD was still subject to tectonic tension during the deposition of $\mathrm{Zn}_{2} d n^{3}$ remains controversial. One view suggests that the $\mathrm{Zn}_{2} d n^{3}$ was only deposited in either the restricted basin $[28,29]$, interplatform basin, or deep shelf [30]. Another view is that the initial tectonic tension began during $\mathrm{Zn}_{2} d n^{3}$ deposition, which includes the formation of either the Chengdu-Luzhou Aulacogen [31, 32] or the Mianzhu-Changning Intracratonic Sag [33]. The most widely accepted view suggests that large-scale tensile processes began in the Early Cambrian, which is consistent with the WSCB of the Upper Yangtze area. This was primarily characterized using the formation of the MY-CN IS, which was also the main indicator of the Xingkai taphrogenesis II episode.

The initial extension during the Late Sinian Dengying period was proceeded by the Sichuan Craton that underwent a period of weak extension in the Early Cambrian. The thickness of the Lower Cambrian Maidiping and the Qiongzhusi formations in the NSWSCD shows that the northern 

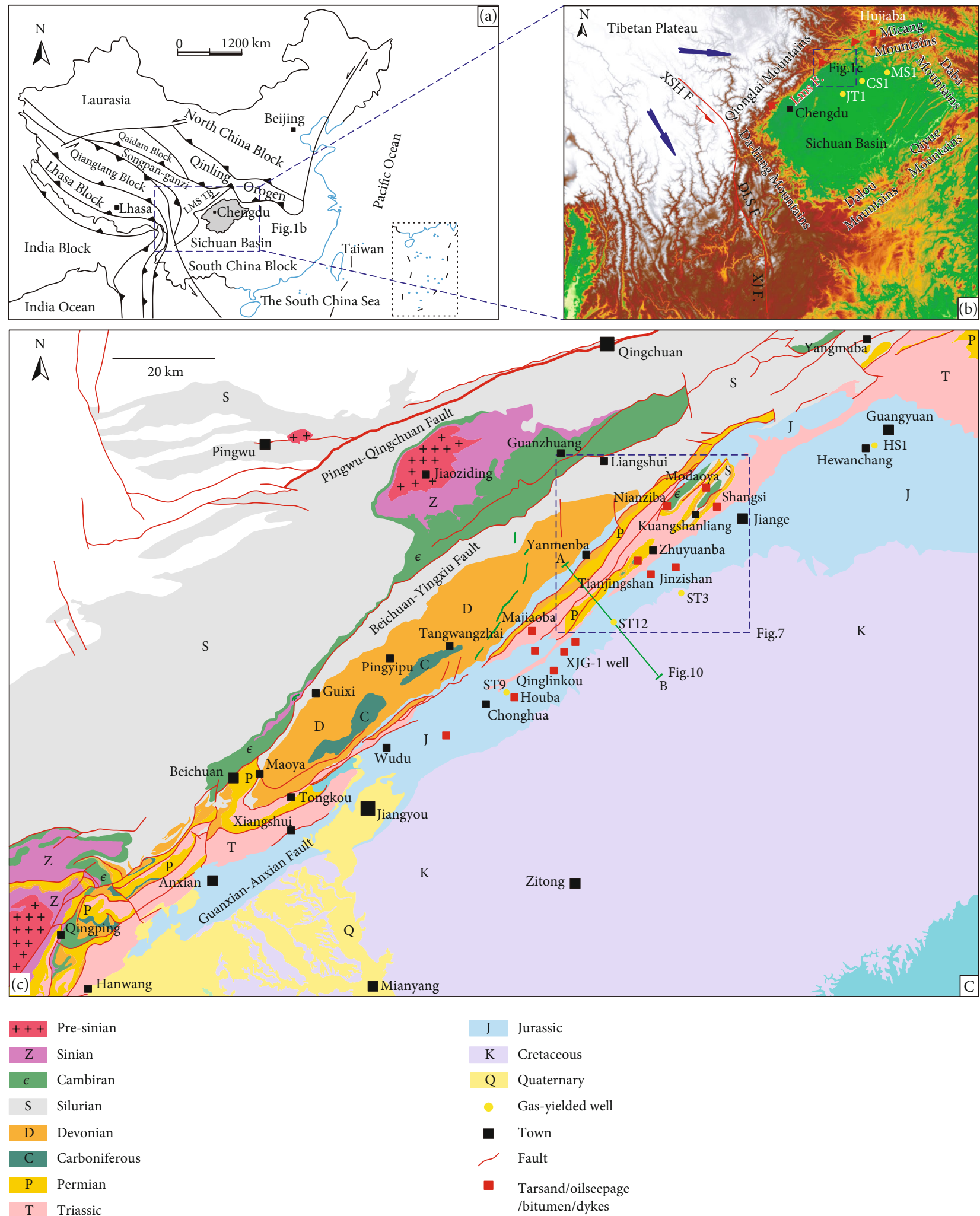

FIGURE 1: (a) Simplified map of China that shows the location of the Sichuan Basin (gray). (b) Simplified digital elevation map that shows the location of the Sichuan Basin on the eastern boundary of the Tibetan Plateau. The northern segment of the western Sichuan depression (NSWSCD) is at the basin-mountain junction [1] of the Longmenshan Thrust Belt (LMS TB). The blue box represents the main study area. (c) 1:200,000 geological map of the NSWSCD, which shows the distribution of oil and gas plays (red frame) in the Houba, Qinglinkou, Tianjingshan, Shangsi, and Nianziba areas. 


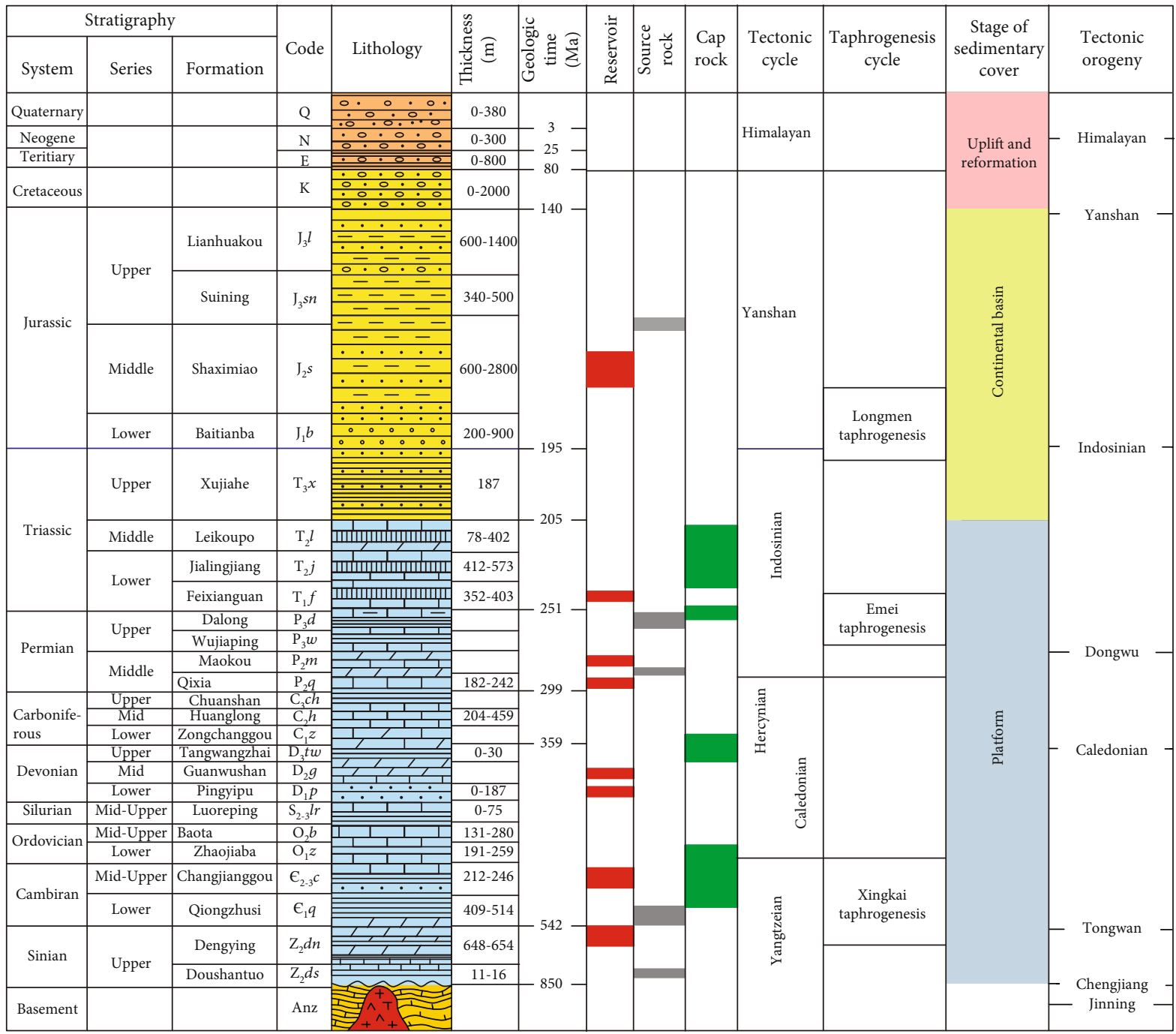

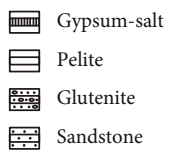

登: Mudstone

茞 Limestone

Dolomite

FIGURE 2: Generalized stratigraphic column of the western Sichuan depression (WSCD). Simplified stratigraphic units with major marker beds, age constraints, and tectonic orogenic events from the Sinian (Ediacaran) Doushantuo Fm, Dengying Fm, and Lower Cambrian Qiongzhusi Fm to the middle Permian Qixia Fm in the WSCD.

segment of the MY-CN IS also experienced an initial extension period during the deposition of the Maidiping Fm. This included extension peaking during the deposition of the Qiongzhusi Fm [34].

2.2. Paleo-Oil Reservoir Evaluation: Review. Although statistical records are incomplete, more than 200 oil seeps, heavy oil, tar sands, and solid bitumen veins are identified in this area [35]. The widespread distribution of paleo-oil reservoirs in the NSWSCD indicates a large-scale hydrocarbon migration and accumulation process in this region.

Petroleum geologists have performed numerous studies on the significance and scale [36-39], oil-to-source correlation [40-49], and petroleum generation timing [50-52] of paleo-oil reservoirs in the NSWSCD. Additionally, there exists a lack of effective reconciliation of geologic history, classification, and level of contribution from Sinian and Cambrian source rocks $[44,49]$. This is caused by the possibility of a mixed Upper Paleozoic source $[41,51]$ and the timing controversy of petroleum generation at 550, 440, or $180 \mathrm{Ma}$, which is based on Re-Os isotopic dating [50-52].

\section{Oil-Source Correlation of Tianjingshan Paleo-Petroleum System}

\subsection{Marine Source Rocks and the Distribution of Paleo- Oil Reservoirs}

3.1.1. Source Rocks. According to detailed geological analysis, the potential source rocks in the NSWSCD include the upper 


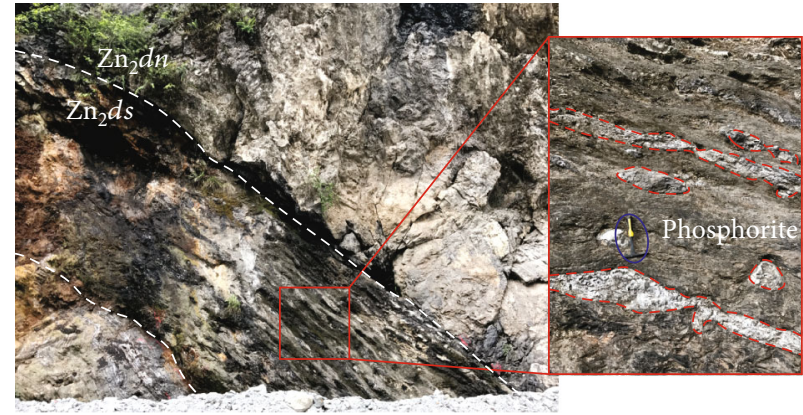

(a)

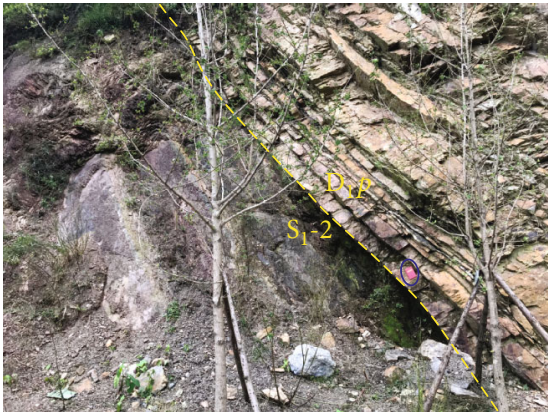

(d)

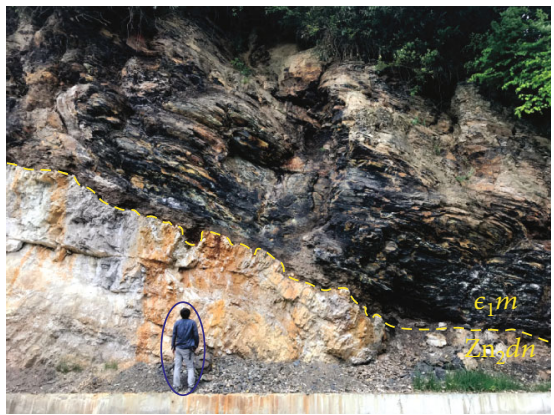

(g)

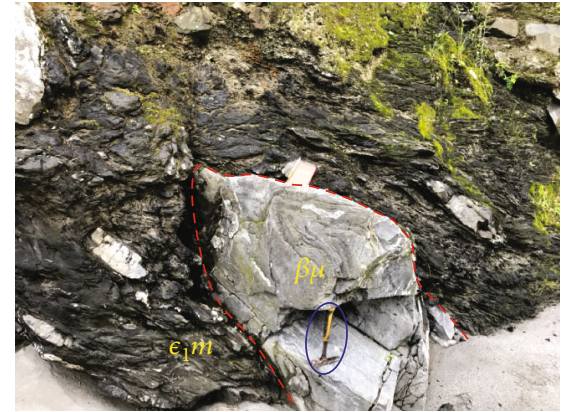

(b)

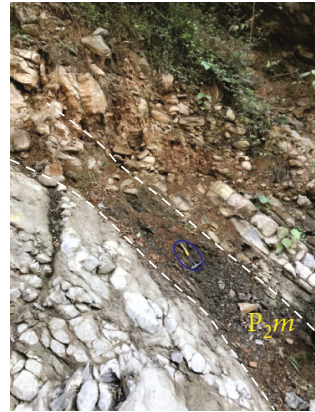

(c)

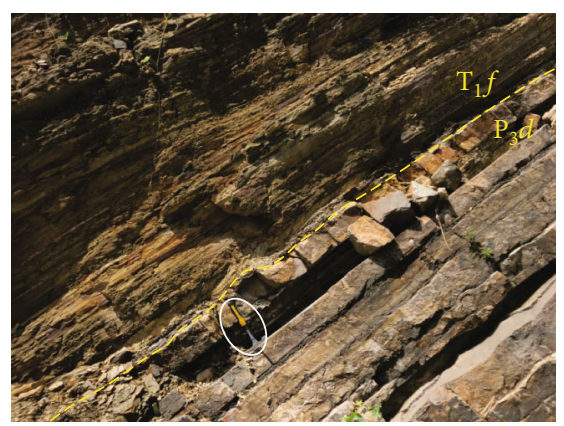

(e)

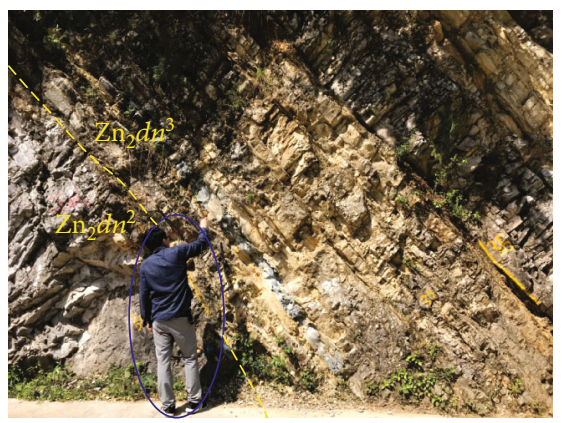

(h)

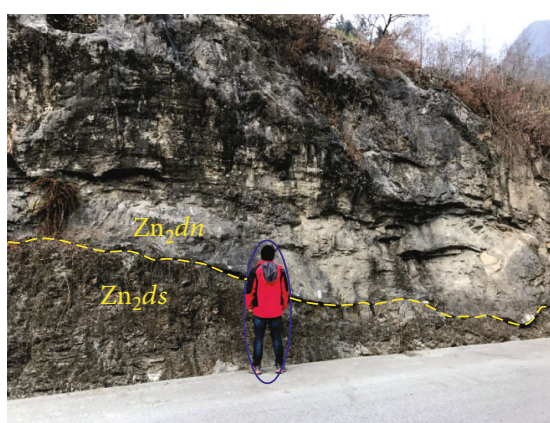

(f)

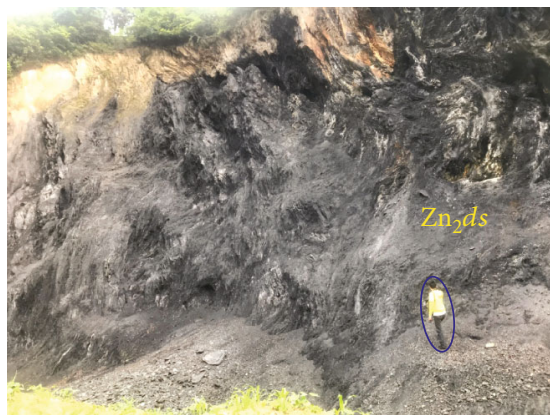

(i)

FIgURE 3: Lithofacies photos of source rocks in the Longmenshan-Michangshan area. (a) Paraconformity of the Doushantuo Fm and Dengying Fm, Qingping, Hanwang. The top of the Doushantuo Fm has interbedded black mudstones and phosphorite. (b) QP-6 is the Lower Cambrian Maidiping Fm with diabase dyke intrusion, at Qingping, Hanwang. (c) GY-7 is the nodular limestone interbedded with thin black shale, which has oil intrusion, at Changjianggou, Shangsi. (d) Paraconformity between the Lower-Middle Silurian gray shale and the Lower Devonian Pingyipu Fm, at Yanmenba, Jiangyou. (e) HY-GYCJG/CJG-11, P/T Boundary, and paraconformity between the Upper Permian Dalong Fm and the Lower Triassic Feixianguan Fm, at Changjianggou, Shangsi. (f) Suspected paraconformity between the Doushantuo and Dengying formations, which has bitumen infill at the boundary, at Guanzhuan, Qingchuan. (g) E/C Boundary and paraconformity between the Dengying and Qingzhusi formations, at Daba, Guangwushan. (h) Conformable contact of the third (clasolite) and second (dolomite) members of the Dengying Fm, at Hujiaba, Ningqiang. (i) Black shale of the Doushantuo Fm, at Nanping and Da'an, Ningqiang.

Sinian Doushantuo Fm, the third member of the upper Sinian Dengying Fm, the Lower Cambrian Qiongzhusi Fm, the Silurian Longmaxi Fm, the interbedded mudstones of the Middle Permian Qixia-Maokou Fm, and the Upper Permian Dalong Fm.

The Lower Cambrian Maidiping Fm-Qiongzhusi Fm $\left(\epsilon_{1} m-q\right)$ source rock that is controlled by the MY-CN IS is particularly thick and is widely distributed in the NSWSCD area. In addition to the good outcrops of black shale that occur in the Mianzhu, Qingchuan, and Nanjiang areas, the deeply buried Lower Cambrian source rocks have been dis- covered by the Jiaotan-1 (JT-1), Mashen-1 (MS-1), and Chuanshen-1 (CS-1) wells (Figures 3(a) and 3(i)).

The organic-rich black shale of the Sinian Doushantuo Fm mainly developed in the second member, which was deposited on the shoreland-continental shelf during extensive transgression [53]. The Doushantuo Fm is thicker toward the edges than in other parts of the Sichuan Basin. Furthermore, the Doushantuo Fm is more developed in the northeast and southeast margins than in the other margins of the Sichuan Basin. The thickness in the northeast Sichuan Basin is $30-90 \mathrm{~m}$. The outcropped mudstone of the Ziyang 


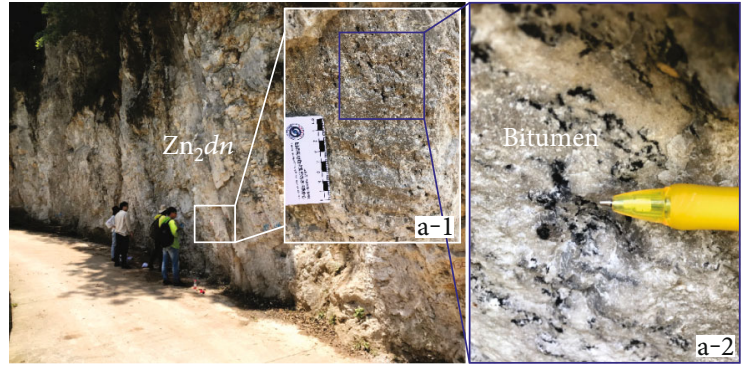

(a)
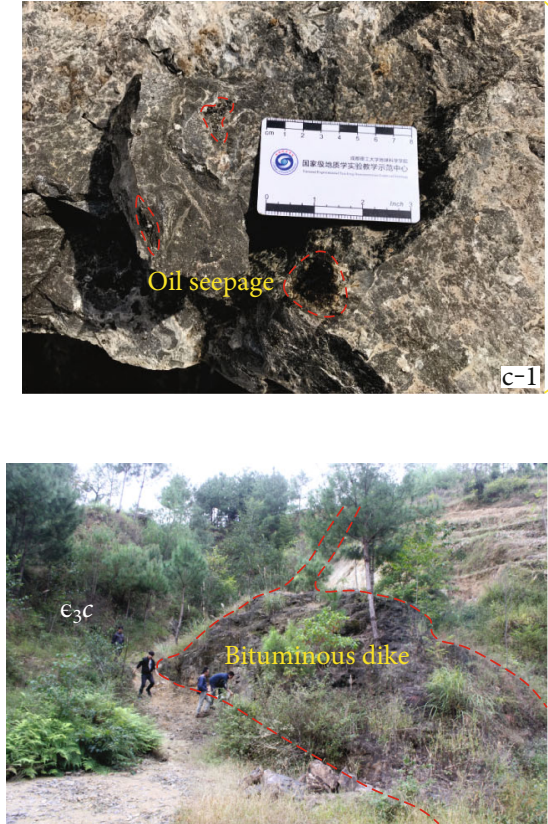

(d)

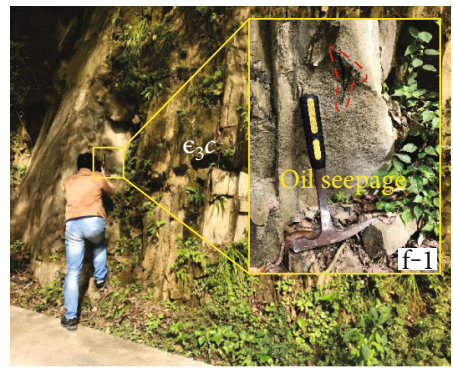

(f)

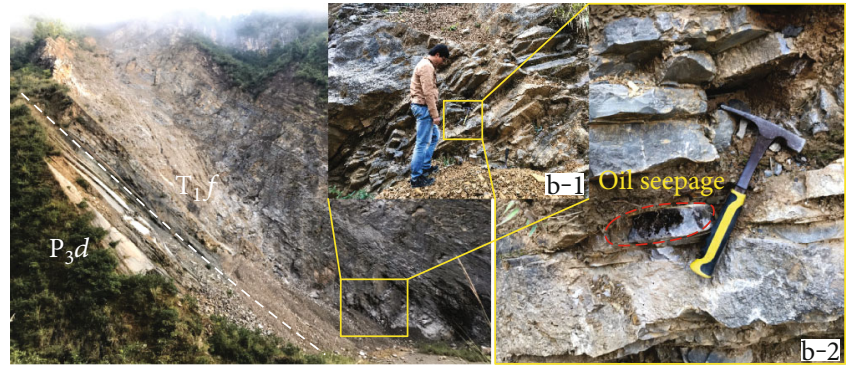

(b)
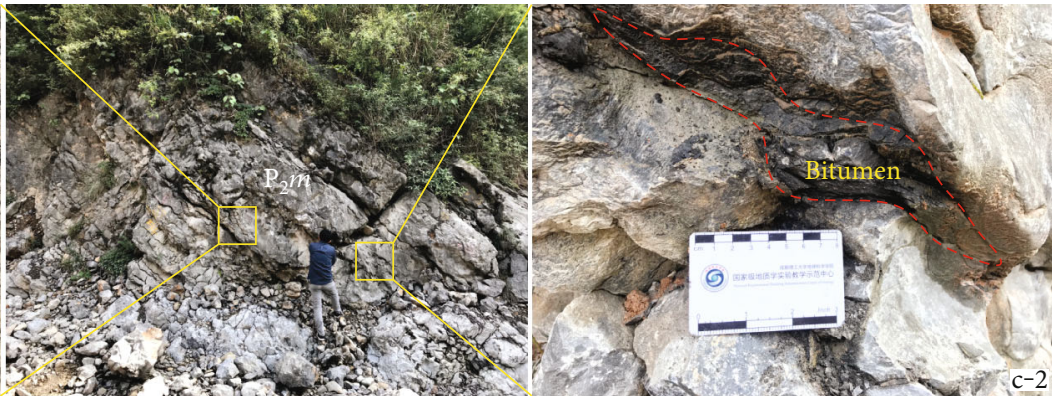

(c)
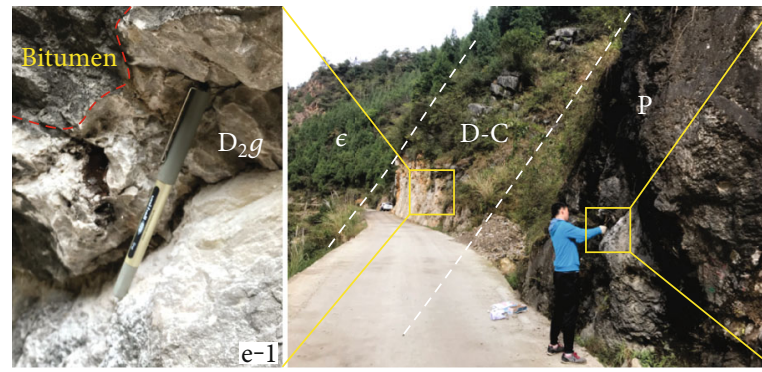

(e)

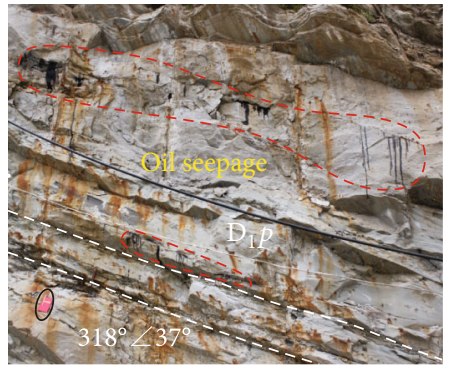

(g)

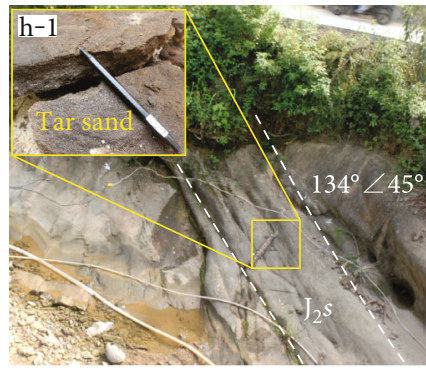

(h)
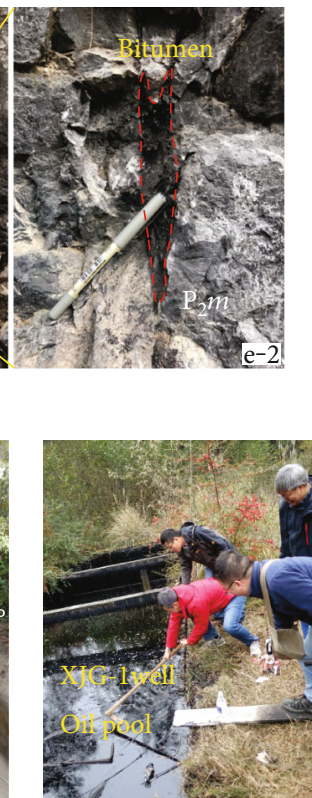

(i)

Figure 4: Paleo-oil reservoir distribution of the Tianjingshan Paleouplift area. (a) Bitumen under the Ediacaran-Cambrian unconformity, located at Dengying Fm, Hujiaba, Ningqiang. (b) CJG-10 is the oil seeps from micrite Feixianguan Fm, located at Changjianggou and Shangsi. (c) GY-7 is the oil seep in stylolite and fractured limestone, located at Changjianggou, Shangsi. (d) TB-8 is the siltstone with large bitumen dyke intrusion, located at Changjianggou Fm, the Nianziba structure. (e) CJG-12 is dry oil seep in dolomite, which is located at Devonian-Permian, Jianfeng. (f) NZB-04 is oil seep in siltstone, which is located at Changjianggou Fm, Jianfeng. (g) TJS-01 is oil seep in siltstone, which is located at Pingyipu Fm and Tianjingshan. (h) QLK-01 is tar sand and oil sand, which is located at Shaximiao Fm, Huanginkou. (i) HB-01 is the oil pool of the Xinjiagou-1 well, which is located at Shaximiao Fm, Qinglinkou.

section is $\sim 96 \mathrm{~m}$. However, the thickness in the southeast is 30-60 $\mathrm{m}$, with the mudstone of the Songlin section $\sim 65 \mathrm{~m}$. The Doushantuo Fm is particularly thin in the interior of the Sichuan Basin, which is generally $10-30 \mathrm{~m}$. The first, second, and third members of the Doushantuo Fm are missing in most areas and have not been verified using sufficient cores.
The potential source rock for the Tianjingshan paleo-reservoir prevents the exposure of the Doushantuo Fm in the TJS PU area. The possible superdeep burial in the NSWSCD has led to no wells being found in this area. The Qingping section is located in the transitional area between the middle and northern segments of the WSCD. The Qingping section is a black 
siliceous mudstone-shale interbedded phosphorite that overlies the Doushantuo Fm (Figure 3(a)). The total organic carbon (TOC) value is 5.17 , but the lithology is relatively thin $(5 \mathrm{~m})$ and is not exposed elsewhere in the WSB.

Thin ( $2 \mathrm{~m})$ black mudstone, which is similar to the Douzantuo Fm, also crops out in the Qingping section. The third member of the Sinian Dengying Fm is thick in the Ningqiang (Hujiaba) section. However, the third member contains thick sets of terrigenous clastic rock (Figure 3(h)). The third member of Sinian Dengying Fm, which has thin mudstones and variable lithofacies, should not be considered an important hydrocarbon-generating layer in the NSWSCD. Additionally, the Ordovician and Silurian have variable periods of hiatus in this study area. When compared with the widely distributed organic-rich shale of the Wufeng-Longmaxi Fm in the central and southern Sichuan Basin, the Silurian in the NSWSCD is dominated by gray shale (Figure 3(d)), and the lower black shale of the Silurian sequence is absent. The black mudstones are also developed in the Middle Permian Qixia and Maokou Fm but are very thin (Figure 3(c)). Therefore, the formation also cannot represent the main source of rock. The Upper Permian Longtan Fm $\left(\mathrm{P}_{3} l\right)$ transforms into the Wujiaping Fm $\left(\mathrm{P}_{3} w\right)$ in this area, which has depositional characteristics suggestive of melanic deep-water silicalite. Notably, during the Late Permian and Early Triassic, the formation and evolution of the Guangwang, Kaijiang, and Liangping Intracratonic Sag led to the development of the Dalong Fm $\left(\mathrm{P}_{3} d\right)$ source rock in the Guangyuan area of the NSWSCD (Figure 3(e)). Thick and widely distributed black siliceous mudstones crop out in the Changjianggou section (Guangyuan area, northern NSWSCD). These are potentially important hydrocarbon generation formations for the Tianjingshan paleo-oil reservoirs.

3.1.2. Paleo-Oil Reservoirs. The reservoirs of the Dengying Fm in the NSWSCD are well developed. Furthermore, the large-scale paleo-oil reservoir of the Dengying Fm is wellmatched with the Lower Cambrian source rocks. Numerous bitumen fillings can be seen in the pores of the Hujiaba (Ningqiang) and Yangba (Nanjiang) sections (Figure 4(a)). The widely distributed bitumen in the Dengying Fm can be linked to paleo-oil reservoirs in the TJS PU area. The frontal and deformation zone of the NSWSCD (TJS PU area) has a highly dense distribution of paleo-oil reservoirs (oil and gas plays). According to the division of the northern, middle, and southern segments of the TJS PU, the paleo-reservoir in the northern segment of the TJS PU contains mainly solid bitumen veins or oil seeps in the Changjianggou Fm. This is located at the core of the Nianziba-Kuangshanliang structure (Figures 4(d) and 4(f)). Additionally, the oil seeps in the monoclinic Qixia-Maokou-Feixianguan Fm of the Changjianggou (Shangsi) section (Figures 4(b) and 4(e)). There are Pingyipu Fm oil seeps between the layers of the overlying Middle-Upper Cambrian and in the upside of the Permian and Triassic, which is located in the middle segment of the TJS PU (Figure 4(c)). There is also intermediate Lower Devonian Pingyipu Fm oil seep in the southern and northern segments. Specific analysis of the time-space sequence in this area is important. Among the samples taken from the southern TJS PU were Jurassic oil sands from the Houba area and heavy oil samples from the Xinjiagou-1 well (Figures 4(h) and 4(i)). The southeast flank of the Shuigentou-Wuhuadong structure shows a monoclinic surface structure. The heavy oil samples from the XJG-1 well can show variations in the maturity and degree of biodegradation of the surface tar sand samples.

3.2. Materials and Methods. More than 20 samples were collected for the oil-to-source correlation that was based on TOC, $R_{o}$, GC-MS, and $\delta^{13} \mathrm{C}$ analyses. These include two bitumen samples from the Sinian Dengying Fm, bitumen, and oil-seep sample from the Lower Cambrian Changjianggou Fm. Furthermore, samples in the upper formations are oilseep sample from the Lower Devonian Pingyipu Fm, two oil-seep samples taken from the Middle Permian QixiaMaokou Fm, and two tar sand/oil-seep samples from the Middle Jurassic Shaximiao Fm. Moreover, included two source rock samples from the Sinian Doushantuo Fm, three source rock samples were taken from the Lower Cambrian Maidiping-Qiongzhusi Fm, the Upper Permian Dalong Fm, and Lower Triassic Feixianguan Fm (Table 1).

Organic geochemistry experiments on source rock and paleo-oil reservoir samples were conducted at the Guangzhou Institute of Geochemistry, Chinese Academy of Science. According to the temperature conversions of $7500 \mathrm{~m} / 170^{\circ} \mathrm{C}$ and $8000 \mathrm{~m} / 190^{\circ} \mathrm{C}$ in the ST -6 and CS -1 wells, respectively, the TJS PU area has a low geothermal gradient of $2.0-2.2^{\circ} \mathrm{C} / 0.1 \mathrm{~km}$. Additionally, most samples in the NW Sichuan Basin have suitable maturity for biomarker analysis. The sample pretreatments mainly use the Soxhlet extraction (Soxh) method, whereas others use the Hydropyrolysis (HyPy) method for comparison.

Hydropyrolysis experiments were performed in a fixed bed reactor using high pressure $(15 \mathrm{MPa}, 4 \mathrm{~L} / \mathrm{min})$ hydrogen gas with a catalyst of ammonium dioxydithiomolybdate $\left[(\mathrm{NH} 4)_{2} \mathrm{MoO}_{2} \mathrm{~S}_{2}\right][54,55]$. The HyPy method using biomarker geochemistry can reduce the thermal maturation effect on biomarkers $\left(R_{o} \leq 2.4 \%\right)$ and migrated hydrocarbons to a great extent. The covalently bound biomarkers released by HyPy are useful in the study of biomarker geochemistry and oil-source correlation on highly overmature source rocks [56]. The advantages of HyPy and its additional details are described in Liao et al. and $\mathrm{Wu}$ et al. $[56,57]$. The saturated and aromatic hydrocarbon fractions were analyzed using GC-MS. The stable carbon isotope analysis of kerogen and extract GC-C-IRMS measured fractions (bulk $\delta^{13} \mathrm{C}$ values). The standard deviation of GC-C-IRMS for each compound was less than $0.3 \%$.

\subsection{Oil-to-Source Correlation}

\subsubsection{Geochemical Characteristics of Potential Source Rocks}

(1) Doushantuo Formation. The mudstone of Doushantuo Fm in the eastern margin of the Sichuan Basin has an average TOC of $1.51 \%$, which is consistent with sapropel-type kerogen and an average carbon isotope value of $-30.90 \%$. The equivalent $R_{o}$ of the Doushantuo Fm generally reaches $3.46-3.82 \%$, which indicated the postmature stage [58]. The 
TABLE 1: Characteristics of source rock and paleo-oil reservoir samples.

\begin{tabular}{|c|c|c|c|c|c|c|c|}
\hline Category & Sample & Formation & Description & Sample point & $R_{o}$ & TOC & Method (Soxh/HyPy) \\
\hline \multirow{5}{*}{ Source rock } & $\begin{array}{c}\text { ZYSL- } \\
120\end{array}$ & Doushantuo/Zn ${ }_{2} d s$ & Mudstone & Songlin, Zunyi & 3.50 & 1.20 & $\sqrt{ } / \sqrt{ }$ \\
\hline & QP-6 & Maidiping/ $€_{1} m$ & Siliceous-mud rock & Qingping, Hanwang & $\mathrm{R}_{\mathrm{b}} 1.56$ & 12.95 & $\sqrt{ } / \sqrt{ }$ \\
\hline & CS1-8140 & Qiongzhusi/ $€_{1} q$ & Siliceous-mud rock & CS-1 well & $\mathrm{R}_{\mathrm{b}} 1.52$ & 2.56 & $\sqrt{ } / \sqrt{ }$ \\
\hline & NJ-S-2 & Guojiaba/ $€_{1} g$ & Mudstone & Yangba, Nanjiang & 4.05 & 4.05 & $\sqrt{ } / \sqrt{ }$ \\
\hline & GYCJG & Dalong/ $/ \mathrm{P}_{3} d$ & Mudstone & Changjianggou, Shangsi & 0.58 & 8.75 & $\sqrt{ } / \sqrt{ }$ \\
\hline \multirow{9}{*}{ Paleo-oil reservoir } & YB-1 & Dengying/ $/ \mathrm{Zn}_{2} d n$ & Reservoir bitumen & Yangba, Nanjiang & $\mathrm{R}_{\mathrm{b}} 3.26$ & - & $\sqrt{ } / \sqrt{ }$ \\
\hline & NZB-4 & $\begin{array}{c}\text { Changjianggou/ } \\
{ }_{2} c\end{array}$ & Oil-seepage & Jianfeng & $\mathrm{R}_{\mathrm{b}} 0.26$ & - & $\sqrt{ } / x$ \\
\hline & TB-8 & $\begin{array}{c}\text { Changjianggou/ } \Theta_{1-} c \\
{ }_{2} c\end{array}$ & Solid bitumen vein & Nianziba & 0.51 & - & $\sqrt{ } / \sqrt{ }$ \\
\hline & TJS-1 & Pingyipu/ $\mathrm{D}_{1} p$ & Oil-seepage & Tianjingshan & $\mathrm{R}_{\mathrm{b}} 0.65$ & - & $\sqrt{ } / \sqrt{ }$ \\
\hline & CJG-12 & Qixia/ $\mathrm{P}_{2} q$ & Oil-seepage & Jianfeng & - & - & $\sqrt{ } / x$ \\
\hline & GY-7 & Maokou/ $\mathrm{P}_{2} m$ & Oil-seepage & Changjianggou, Shangsi & - & - & $\sqrt{ } / x$ \\
\hline & CJG-10 & Feixianguan $/ \mathrm{T}_{1} f$ & Oil-seepage & Changjianggou, Shangsi & 0.94 & - & $\sqrt{ } / x$ \\
\hline & QLK-1 & Shaximiao $/ J_{2} s$ & Tar sand & Qinglinkou & $\mathrm{R}_{\mathrm{b}} 0.41$ & - & $\sqrt{ } / \sqrt{ }$ \\
\hline & HB-1 & Shaximiao $/ J_{2} s$ & Oil & Xinjiagou-1 well & 1.03 & - & $\sqrt{ } / \sqrt{ }$ \\
\hline
\end{tabular}

GC-MS results of HyPy for saturates of the Doushantuo Fm with a high thermal maturity still have an indistinguishable hump (UCM). Terpanes and regular steranes are also missing.

(2) Dalong Formation. Controlled by the GuangwangKaijiang-Liangping Intracratonic Sag, the Upper Permian Dalong Fm $\left(\mathrm{P}_{3} d\right)$ is marine gray-black siliceous rock interbedded with black shales. The Upper Permian Dalong Fm is mainly found in the Guangyuan area. The thickness of the Dalong Fm ranges from 17 to $40 \mathrm{~m}$. High TOC values $(4.58-8.75 \%)$ in the Changjianggou section indicate that the Dalong Fm has considerable petroleum potential for the Permian Qixia-Maokou Fm and Trasssic Feixianguan Fm.

The $\mathrm{C}_{23}$-tricyclic terpane/ $\mathrm{C}_{24}$-tetracyclic terpane $\left(\mathrm{TT}_{23} / \mathrm{tT}_{24}\right)$ ratios of the Dalong Fm range from 1.2 to 1.6 [56]. The values of gammacerane $/ \mathrm{C}_{30}-\alpha \beta$ hopane $\left(\mathrm{Gam} / \mathrm{H}_{30}\right)$ are only 0.09 . The distributions of $\mathrm{C}_{27}-\mathrm{C}_{29} \alpha \alpha \alpha R$ steranes in the Dalong Fm show similar " $V$ " shapes $\left(\mathrm{C}_{27}>\mathrm{C}_{29}>\mathrm{C}_{28}\right.$, Figure 5). The maturity-related parameters such as $20 \mathrm{~S} /(20$ $S+20 R)$ and $\beta \beta /(\alpha \alpha+\beta \beta)$ for $\mathrm{C}_{29}$-regular steranes $\left(\mathrm{C}_{29}-\beta \beta /[\alpha \alpha+\beta \beta]\right.$ and $\left.\mathrm{C}_{29}-\beta \beta /[\alpha \alpha+\beta \beta]\right)$ are 0.45 and 0.56 , respectively. $\mathrm{C}_{23}$-tricyclic terpane/ $\mathrm{C}_{30}-\alpha \beta$ hopane (TT23/H30) ranges from 0.10 to 0.30 . Ts/(Ts $+\mathrm{Tm})$ range from $0.17-0.22$. The ratios of $\mathrm{C}_{27} \beta \alpha(20 \mathrm{R}) / \mathrm{C}_{27} \alpha \alpha(20 \mathrm{R})$-steranes range from 0.08 to 0.15 . These maturity parameters were consistent with the maturity of the Dalong Fm in the TJS PU area $\left(R_{o} 0.58 \%\right)$. This is lower than those in the eastern segment of the Kaijiang-Liangping Intracratonic Sag (NE Sichuan Basin). The uplift of the Longmen Mountains causes the Dalong Fm in the Guangyuan area to be in the early stages of oil generation. It may only charge the stratigraphically adjacent formation (Permian-Triassic) because of the limited extent and relatively low maturity.
(3) Maidiping-Qiongzhusi Formation. The kerogens of the Qiongzhusi Fm in the WSB are dominated by micrinite (more than 95\%), with less than 5\% content of marine vitrinite and intertinite. The Lower Cambrian source rocks in the NSWSCD generally have high TOC values and maturity. This creates significant petroleum potential for the Sinian Dengying Fm and the Upper Paleozoic [59]. The TOC value of the silicate-mudstone in the CS-1 well (burial depth 8 $140 \mathrm{~m}$ ) is 2.56. The thickness of the Qiujiahe Fm (equivalent to the Madiping Fm) in the Qingping section is $142 \mathrm{~m}$. This was tested using 26 equidistant samples with average TOC and $R_{\mathrm{o}}{ }^{b}$ values of $12.95 \%$ and $2.31 \%$. The thickness of the exposed Qingchuan section is $80 \mathrm{~m}$, and the average TOC for 15 equidistant samples was $2.2 \%$. The adjacent north Sichuan basin shows that the Guojiaba Fm (equivalent to the Qiongzhusi Fm) of the Yangba and Daba sections also has high TOC values of $2.87-3.79 \%$.

The GC-MS of two superdeep samples (8140 $\mathrm{m}$ and $7894 \mathrm{~m}$ from the CS-1 well) show the complete distribution of $n$-alkanes. Steranes originate from the sterols of eukaryotic organisms [60]. The stable distribution of $\mathrm{C}_{27}-\mathrm{C}_{29}$ regular steranes in the generative windows can effectively distinguish oils from the same source rock with different organic phases $[61,62]$. The distributions of $\mathrm{C}_{27}-\mathrm{C}_{29}$ steranes in the CS-1 well have a similar " $\mathrm{L}-\mathrm{V}$ " shape of $\mathrm{C}_{27} \geq \mathrm{C}_{27}>$ $\mathrm{C}_{28}$ (Figure 5). This is similar to the Dalong Fm. The $\mathrm{C}_{23}$-tricyclic terpane/ $\mathrm{C}_{24}$-tetracyclic terpane $\left(\mathrm{TT}_{23} / \mathrm{tT}_{24}\right)$ ratios of the $8140 \mathrm{~m}$ sample are 2.74 . The $\mathrm{C}_{29}-20 S /(20 S+20 R)$ and $\beta \beta /(\alpha \alpha+\beta \beta)$ rise from 0 to $\sim 0.5(0.52-0.55$ endpoint) and from 0 to $\sim 0.7$ ( $0.67-0.71$ endpoint), respectively, with the increase in isomerization $[60,62]$. The $\mathrm{C}_{29}-20 \mathrm{~S} /(20 \mathrm{~S}+20 \mathrm{R}$ ) are approximately $0.41-0.42$, and $\mathrm{C}_{29}-\beta \beta /(\alpha \alpha+\beta \beta)$ is approximately 0.36 (Table 2 ), which is significantly similar to the north Sichuan Basin. The north Sichuan Basin ranges 


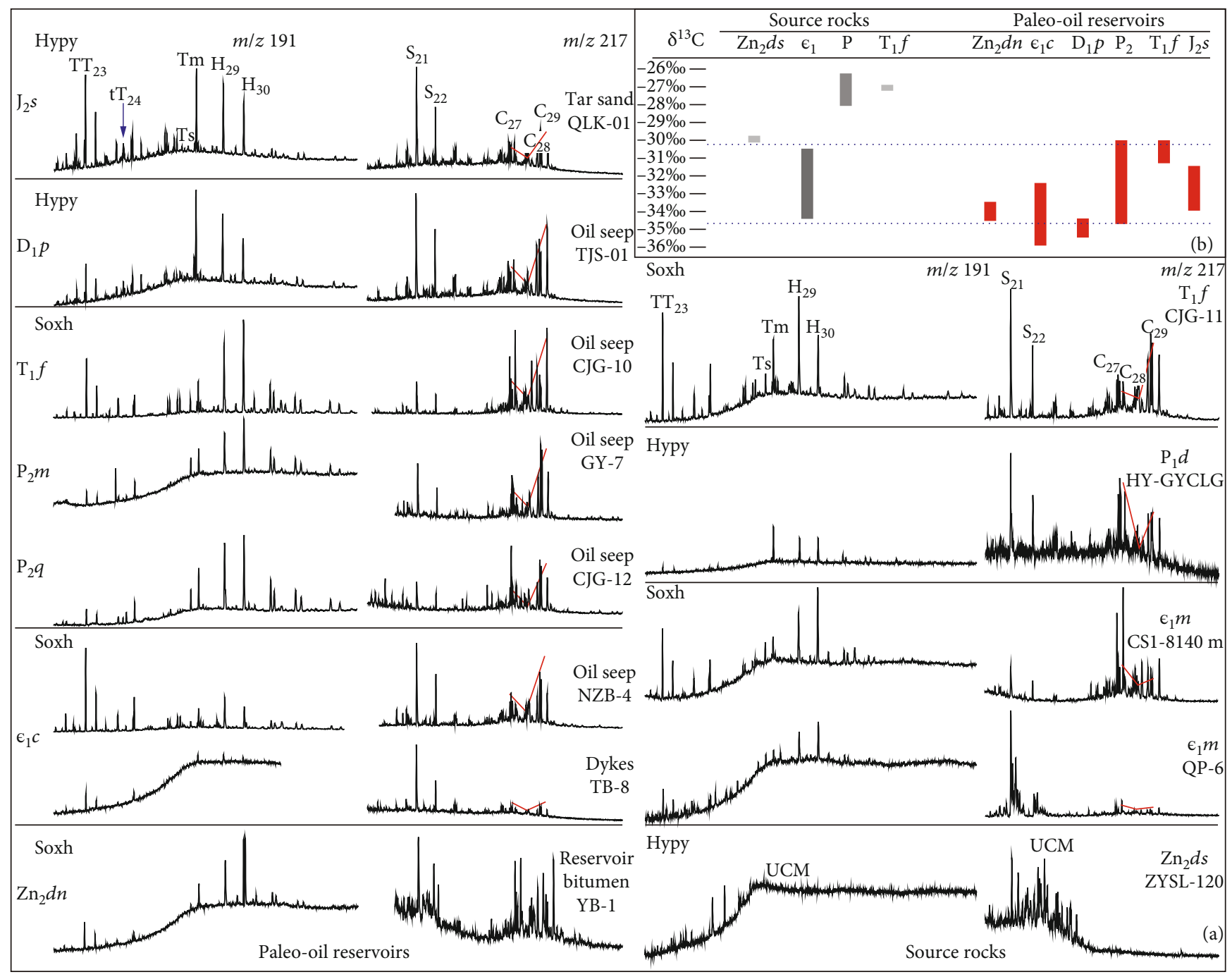

Figure 5: The GC-MS and $\delta^{13} \mathrm{C}$ characteristic of paleo-oil reservoirs and source rocks in the Tianjingshan Paleouplift area. (a) The GC-MS shows that the distribution of the $\mathrm{C}_{27}-\mathrm{C}_{29}$ regular steranes $\left(\mathrm{C}_{29}>\mathrm{C}_{27}>\mathrm{C}_{28}\right)$ is similar in both the Sinian Dengying and Jurassic Shaximiao formations. The paleo-oil reservoirs show that the $\mathrm{TT}_{23} / \mathrm{tT}_{2} 4$ values can also possibly correlate with the source rocks. (b) The distribution interval of the $\delta^{13} \mathrm{C}$ correlation shows that the source for the paleo-oil reservoirs is mainly the Lower Cambrian.

TABLE 2: Biomarker parameters of source rock and paleo-oil reservoir.

\begin{tabular}{|c|c|c|c|c|c|c|c|c|c|c|c|c|c|}
\hline \multirow{3}{*}{ Biomarker parameters } & \multicolumn{4}{|c|}{ Source rock } & \multicolumn{9}{|c|}{ Paleo-oil reservoir } \\
\hline & \multicolumn{2}{|c|}{$€_{1} m+q$} & \multirow{2}{*}{$\begin{array}{c}\mathrm{P}_{2} d \\
\text { GY-S-8 }\end{array}$} & \multirow{2}{*}{$\begin{array}{c}\mathrm{T}_{1} f^{1} \\
\text { CJG-11 }\end{array}$} & \multirow{2}{*}{$\begin{array}{c}\mathrm{Zn}_{2} d n^{4} \\
\mathrm{YB}-1\end{array}$} & \multicolumn{2}{|c|}{$\epsilon_{1} c$} & \multirow{2}{*}{$\begin{array}{c}\mathrm{D}_{1} p \\
\text { TJS-1 }\end{array}$} & \multirow{2}{*}{$\begin{array}{c}\mathrm{P}_{2} q \\
\text { CJG-12 }\end{array}$} & \multirow{2}{*}{$\begin{array}{l}\mathrm{P}_{2} m \\
\mathrm{GY}-7\end{array}$} & \multirow{2}{*}{$\begin{array}{c}\mathrm{T}_{1} f \\
\text { CJG-10 }\end{array}$} & \multicolumn{2}{|c|}{$\mathrm{J}_{2} \mathrm{~s}$} \\
\hline & CS1-8140 & QP-6 & & & & TB-8 & NZB-4 & & & & & QLK-1 & HB-01 \\
\hline $\mathrm{TT}_{23} / \mathrm{tT}_{24}$ & 2.74 & 1 & 1.1 & 2.57 & 3.37 & 2.68 & 2.78 & 2.73 & 2.48 & 3.46 & 1.9 & 3.70 & 3.32 \\
\hline $\mathrm{TT}_{23} / \mathrm{H}_{30}$ & 0.7 & 0.67 & 0.28 & 1.25 & 0.29 & 1.96 & 2.4 & 1.8 & 0.14 & 0.17 & 0.39 & 1.53 & 1.8 \\
\hline $\mathrm{H}_{29} / \mathrm{H}_{30}$ & 0.78 & 0.74 & 0.91 & 1.49 & 0.79 & 1.78 & 1.42 & 1.45 & 0.88 & 0.71 & 0.75 & 1.39 & 1.17 \\
\hline $\mathrm{Ts} / \mathrm{Ts}+\mathrm{Tm}$ & 0.5 & 0.5 & 0.17 & 0.29 & 0.12 & 0.27 & 0.23 & 0.27 & 0.33 & 0.41 & 0.31 & 0.49 & 0.48 \\
\hline $\mathrm{C}_{29}-20 S /(20 S+20 R)$ & 0.4 & 0.42 & 0.44 & 0.48 & 0.46 & 0.44 & 0.46 & 0.46 & 0.46 & 0.47 & 0.37 & 0.49 & 0.46 \\
\hline $\mathrm{C}_{29}-\beta \beta /(\alpha \alpha+\beta \beta)$ & 0.37 & 0.36 & 0.52 & 0.51 & $0.27-0.44$ & 0.58 & 0.58 & 0.56 & 0.56 & 0.57 & 0.3 & 0.59 & 0.6 \\
\hline $\mathrm{S}_{21} / \mathrm{S}_{22}$ & 3.75 & 2.28 & 1.19 & 2.46 & 2.77 & 2.62 & 1.99 & 2.08 & 2.34 & 2.49 & 2.37 & 2.39 & 2.63 \\
\hline $\mathrm{S}_{21}+\mathrm{S}_{22} / \mathrm{C}_{27}+\mathrm{C}_{28}+\mathrm{C}_{29}$ & 0.43 & 0.12 & 0.33 & 0.36 & 0.19 & 0.96 & 0.35 & 0.42 & 0.13 & 0.19 & 0.1 & 0.33 & 0.44 \\
\hline $\mathrm{C}_{27} /\left(\mathrm{C}_{27}+\mathrm{C}_{28}+\mathrm{C}_{29}\right)$ & 37 & 38 & 39 & 23 & 27 & 29 & 24 & 23 & 29 & 23 & 28 & 28 & 27 \\
\hline $\mathrm{C}_{28} /\left(\mathrm{C}_{27}+\mathrm{C}_{28}+\mathrm{C}_{29}\right)$ & 31 & 32 & 31 & 25 & 31 & 30 & 27 & 23 & 23 & 21 & 32 & 22 & 22 \\
\hline $\mathrm{C}_{29} /\left(\mathrm{C}_{27}+\mathrm{C}_{28}+\mathrm{C}_{29}\right)$ & 32 & 30 & 30 & 52 & 42 & 44 & 49 & 54 & 48 & 56 & 40 & 50 & 51 \\
\hline
\end{tabular}


from 0.31 to 0.40 using Soxh and HyPy [48]. These deeply buried maturity parameters for the CS- 1 well samples were consistent with a relatively low maturity, which is according to the $R_{o}(1.5 \%)$. Therefore, the deeply buried Lower Cambrian source rocks in the NSWSCD (CS-1 well) may not have reached the high-overmature stage owing to overpressure suppression.

\subsubsection{Geochemical Characteristics of Paleo-Oil Reservoirs}

(1) Terpanes and Regular Steranes. The Dengying Fm reservoir and the Lower Cambrian source rocks are typical hydrocarbon accumulation units of ancient geological age. The maturity-related parameters such as the $\mathrm{C}_{29}-20 \mathrm{~S} /(20 S+20$ $R)$ and $\mathrm{C}_{29}-\beta \beta /(\alpha \alpha+\beta \beta)$ of the Dengying Fm bitumen in the Yangba section range from $\sim 0.42$ to 0.46 and $\sim 0.27$ to 0.44 , which does not reach the endpoint of isomerization. The maturity of the Dengying reservoir bitumen is similar to the Cambrian-Jurassic paleo-oil reservoir $\left(R_{o} 0.5-1.0 \%\right)$ in the TJS PU area. Tricyclic terpanes are common in petroleum and source rock extracts, possibly originate from prokaryotic cell membranes [63], and can be related to Tasmanites [64-67]. The cell structure observation of Tasmanite using optical microscopy shows that tricyclic terpanes first occurred in the Upper Cambrian and were extremely abundant in some Paleozoic strata [68-70]. Tricyclic terpanes are also present in the Upper Permian Dalong Fm in the Tianjingshan structure. Generally, the $\mathrm{C}_{23}$ member is the dominant compound in tricyclic terpanes in crude oils, especially those from marine sources [71]. Moreover, tricyclic terpanes are more resistant to biodegradation than hopanes and can occur in severely biodegraded oil even when the hopanes have been destroyed [72]. The tetracyclic terpanes were derived from the thermal or microbial rupture of hopanes or precursor hopanoids [60]. Tetracyclic terpanes are more resistant to biodegradation than the hopanes [68]. These terpanes are present in a few samples from the TJS PU area. $\mathrm{C}_{24}$ tetracyclic terpane (tT24) is more common than its homologs. Oils sourced from terrestrial organisms have relatively high concentrations of $\mathrm{tT}_{24}[73]$.

The $\mathrm{TT}_{23} / \mathrm{tT}_{24}$ ratio can indicate the type of organic matter. Relatively high values for the $\mathrm{TT}_{23} / \mathrm{tT}_{24}$ ratio usually imply a large input from marine organic matter [74, 75]. The $\mathrm{TT}_{23} / \mathrm{tT}_{24}$ ratios are in the range of 3.0-3.5 in the Qiongzhusi Formation [48], whereas they fall to 1.1-1.6 in the Dalong Formation. However, oils sourced from terrestrial organic matter have a relatively low $\mathrm{TT}_{23} / \mathrm{tT}_{24}$ ratio value. The NW Sichuan Basin has the Qiongzhusi Formation that was deposited in the open sea during the Lower Cambrian [76]. The decreased TT23/tT24 ratio from the Qiongzhusi Fm to the Dalong Fm is consistent with increased terrestrial organic matter input, which can be observed in the composition of macerals. Meanwhile, Wang et al. [41] also identified the characteristics of gravity current deposition in the Dalong Fm in the Sichuan Basin [77]. Therefore, the decrease of the $\mathrm{TT}_{23} / \mathrm{tT}_{24}$ ratio shows a sufficient correlation with the variation in the sedimentary environment. The $\mathrm{TT}_{23} / \mathrm{tT}_{24}$ ratios of the Lower Cambrian paleo-oil reservoir $(\sim 2.7-3.2)$, the
Lower Devonian Pingyipu Fm oil seep ( 2.7), the Permian Qixia-Maokou Fm oil seep ( 2.5-3.5), the Jurassic Shaximiao Fm tar sand and oil ( 3.3-3.7), and the Qiongzhusi Formation $(\sim 2.7-3.2)$ are all approximately similar. However, these differ from the Dalong Fm ( 1.1-1.6). Therefore, it appears that the Lower Cambrian source rocks most likely correlate with the Sinian-Cambrian bitumen, Devonian-Permian, and Jurassic oil seeps.

Pregnane and homopregnane are highly resistant to biodegradation [78]. They are derived from the hormones pregnanol and pregnanone and the thermal cracking of $\mathrm{C}_{27}-\mathrm{C}_{29}$ regular steranes [79]. The pregnane/homopregnane $\left(\mathrm{S}_{21} / \mathrm{S}_{22}\right)$ ratios of the Sinian Dengying Fm and Jurassic Shaximiao Fm paleo-oil reservoir are very similar $(\sim 2.0-2.7)$. These ratios are also similar to that of the Lower Cambrian ( 2.3-2.5) but higher than the Dalong Fm ( 1.1-1.2). This provides additional evidence that the oil seeps and bitumens in the TJS PU area were derived from the same source rock. The paleo-oil reservoir was severely biodegraded. Particularly, the absence of acyclic isoprenoids in the bitumen from the Dengying and Changjianggou formations indicates that those paleo-oil reservoirs rank 5-6 on the PM biodegradation scale [58]. The distributions of the $\mathrm{C}_{27}-\mathrm{C}_{29}$ regular steranes $\left(\mathrm{C}_{29}>\mathrm{C}_{27}>\mathrm{C}_{28}\right)$ in extracts are similar, which was also reported by Huang and Wang (2008) and Rao et al. (2008) [41, 42].

(2) Bulk $\delta 13 C$ Values of Kerogen and Extract Fractions. Stable carbon isotopic compositions have been widely used for correlating oil with source rocks $[61,80]$. The $\delta^{13} \mathrm{C}$ value of oil (bitumen) depends on the original organic matter from which the oil was expelled [81]. A negative shift of bulk $\delta^{13} \mathrm{C}$ values between kerogen and oil/bitumen of less than $3 \%$ usually suggests a possible correlation $[60,82]$. The bulk $\delta^{13} \mathrm{C}$ values of the Precambrian Doushantuo Fm in the Yichang and Zunyi areas range from $-27.9 \%$ to $-30.7 \%$. The bulk $\delta^{13} \mathrm{C}$ values of Lower Cambrian kerogen in the NW Sichuan basin are between $-31.0 \%$ and $-34.0 \%$. However, the bulk $\delta^{13} \mathrm{C}$ values of the Middle-Upper Permian and Lower Triassic kerogen range from $-26.0 \%$ to $-28.0 \%$, which are much higher than those of the Cambrian kerogen (Figure 5(b)).

The bulk $\delta^{13} \mathrm{C}$ values of the Lower Cambrian oil seep and the solid bitumen veins from the Nianziba anticline are $-34 \%$ o to $-36.0 \%$. The bulk $\delta^{13} \mathrm{C}$ value of the Devonian Pingyipu Fm paleo-oil reservoir in Tianjingshan (Middle TJS PU area) is $-34.95 \%$. The $\delta^{13} \mathrm{C}$ values of the Qixia, Maokou, and Feixianguan $\mathrm{Fm}$ range from $-30 \%$ to $-34 \%$. The $\delta^{13} \mathrm{C}$ values of the saturates, aromatics, resins, and asphaltenes of the Jurassic tar sands and oil in the Qinglinkou-Huangjinkou area (Southern TJS PU area) are in the range of $-31.5 \% 0-34.0 \%$. Generally, oils from Paleozoic marine sources have bulk $\delta^{13} \mathrm{C}$ values lighter than $-30 \%$, which gradually became heavier (rich in ${ }^{13} \mathrm{C}$ ) in the following (Permian-Triassic) geologic periods [83]. The Tianjingshan structure shows that paleo-oil reservoirs in different strata (Sinian, Cambrian, Devonian, Permian, Triassic, and Jurassic) have very low $\delta^{13} \mathrm{C}$ values (commonly < $-34.0 \%$ ), which confirmed that those oil seeps and bitumen are mainly from the Lower Cambrian source rocks. 


\section{Petroleum System Interpretation and Discussion}

\subsection{Tectonic-Controlled (Intracratonic Sag and Paleouplift) of Early Hydrocarbon Accumulation}

4.1.1. Northern Segment of the Mianyang-Changning Intracratonic Sag. Along with a full analysis of the regional structural characteristics of China, the formation mechanism of the North China Rift and the structural background of the eruption of the Emeishan Basalt in the southwestern margin of the Sichuan Basin were reported. Therefore, Luo proposed the taphrogenesis theory and proposed that there had been three large-scale taphrogeny in the Chinese mainland since the Late Proterozoic subsequently [84], which include the Xingkai, Emei, and North China [20]. These were closely related to the formation and distribution of oil and gas.

The Early Cambrian MY-CN IS has received extensive attention since being discovered along with the genesis of the Rodinia and Gondwana supercontinents being proposed [10]. The MY-CN IS extends from the original Tethys Ocean into the Sichuan Basin of the Upper Yangtze Craton, which trends along the NNW-SSE. Both sides of the Weiyuan and Gaoshiti structure in the middle segment of the MY-CN IS are used as boundaries. Therefore, intracratonic sag can be divided into three segments. The southern segment spans from Dazu, Yibin, and Longchang to Changning, and the northern segment stretches over Yanting, Langzhong, and Guangyuan area. Currently, the middle-north segment of the WSCD coincides with the northern segment of the MYCN IS. However, because of the greater burial depth of the Sinian Dengying Formation and the Lower Paleozoic, the investigation of the structural features of the northern segment of the intracratonic sag is difficult.

Based on the preliminary analysis of the two-dimensional seismic profile in the Shuangyushi-Shejianhe area, the deeply buried Devonian-Permian structure is located just above the eastern boundary of the MY-SC IS, and scarp features are distinct. The Late Sinian-Early Cambrian tectonic and sedimentary characteristics of the NSWSCD are similar to that of the Gaoshiti-Moxi structure in the central Sichuan Basin. This study has sufficiently used high-precision contiguous 3D seismic and some 2D seismic data (from Sinopec and PetroChina) in addition to drilling and field outcrop data. This was performed using the thickness description method of the Lower Cambrian Maidiping and Qiongzhusi formations that was first discovered in the MY-CN IS (Figure 6(a)).

The boundary on the west side of the northern segment is approximately perpendicular to the original Tethys Ocean and is distributed along the Chengdu-Weiyuan area. The boundary characteristics of the reflected thickness are clear. The eastern part of the northern segment has great depth, is widely distributed, and is more prominent owing to the depositional control of the deep formations in the NSWSCD. The east side of the northern segment lies along the ShehongSantai-Yanting-Langzhong-Jiangyou-Guangyuan line, and the distance between scarps is wider. The thickness differentiation of the Qiongzhusi Fm decreases gradually after passing Shehong. The continuous feature of the Dengying Fm is apparent in the seismic profile below the steeper scarp (I). Similar to that of the central Sichuan Basin, tension faults are not well developed in the northern segment of the MY$\mathrm{CN}$ IS. The clarity of boundary features is relatively reduced. The NSWSCD is in the center of the northern segment of the MY-CN IS, where the Lower Cambrian is thick. The Lower Cambrian marine clasolite is approximately $1000 \mathrm{~m}$ thick and is the sedimentary center of the black organic-rich shale from the Maidiping-Qiongzhusi Fm.

\subsubsection{Stratigraphic Context of the Tianjingshan Paleouplift} Area. Paleouplifts are areas of positive structural relief that form on the Earth's surface owing to the interaction of internal and external geodynamic processes through the geologic time [85]. According to pre-Devonian sedimentary paleomorphology, the study states that there is a paleouplift structure in the northwest of the Sichuan Basin. This was subject to tectonic evolution in the sag and platform areas, which was controlled by the Longmenshan deep faults. This structure was named the TJS PU, with Cambrian-Ordovician denudation in the core of the area [86]. Paleouplifts can control early oil and gas accumulation of ancient deep petroleum systems. The TJS PU is located on the northern side of the Leshan-Longnvsi paleouplift and has a relatively small area. Therefore, a few studies consider the TJS PU to be part of the Caledonian Paleouplift [87].

The TJS PU is poorly constrained in time-space. Outcropping strata are scarce in this area and have poor quality seismic data owing to the complex structural background and lack of Sinian-Cambrian drilling in the region. This caused the precise structural boundary of the TJS PU to be difficult to determine. Controversy also exists regarding the initial uplift time. A few studies believe that the TJS PU formed in the Early Cambrian, which is based on observations of the lithological characteristics of the Lower Cambrian Changjianggou Fm $[85,88]$.

The 1:200,000 regional survey report originally divides the Changjianggou Fm into three members. Revised in 1962, the lower two members still belong to the Changjianggou Fm. However, the upper member belongs to the Modaoya Fm. When the distinct lithologies and lithofacies in this area are considered, drilling has not revealed the relationship of the contact between the top of the Dengying Fm and the bottom of the Lower Cambrian. Whether the Yunnan stratigraphic system should be adopted to correspond the Changiianggou-Modaoya Fm to the Qiongzhusi-Canglangpu Fm is still questionable, respectively. Furthermore, this study corresponds to the Modaoya Fm to the middle-upper part of the Lower Cambrian such as the Yanwangyan Fm in the northern Sichuan Basin. Therefore, the initial uplift time of the TJS PU is slightly different from a few other studies. The TJS PU is vertically superimposed on the MY-CN IS, which is roughly on the west side of scarp (I) in the northern segment of the Early Cambrian MY-CN IS. Based on the stratal relationships and outcrop chronostratigraphy, the TJS PU can also be divided into several zones (Figure 7).

The preserved tectonic features of the N. TJS PU are characterized by two anticlinal structures (the Kuangshanliang and Nianziba structures), which can be traced further 


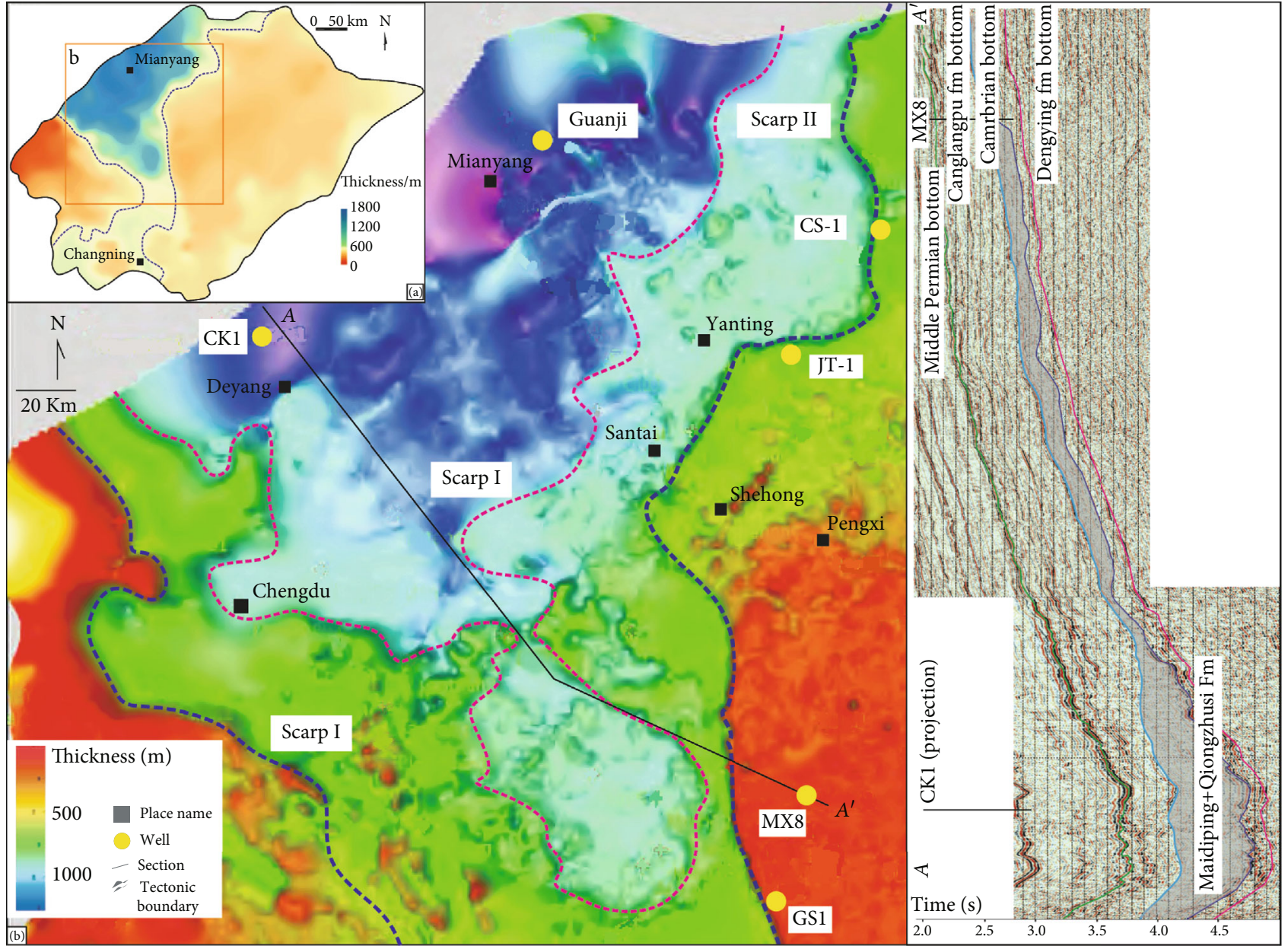

FIGURE 6: Structural characteristics of the northern segment of the Mianyang-Changning intracratonic sag (MY-CN IS). (a) Earlier research results showed that the north segment of the western Sichuan Basin coincides with the northern segment of the MY-CN IS. The relatively rough thickness figure of the Lower Cambrian is from Liu et al. [10]. (b) Latest thickness map of the Lower Cambrian Maidiping Fm and Qiongzhusi Fm from this study. The thickness of the Qiongzhusi Fm has decreased gradually after passing Shehong.

north to Sanliba, Baolun, and Guangyuan area. Finally, the N. TJS PU gradually transects the southwest limb of the Michangshan Paleouplift in the Chaotian. The complete outcrops in the N. TJS PU are found in the current Nianziba structure, which has paraconformable stratigraphic contacts. Combined with the middle and upper part of the Changjianggou Fm, the Middle Ordovician Baota Fm overlies on the third member of the Changjianggou Fm. This includes an overlap from the Middle Silurian Luoreping Fm. Paraconformities also occur in the Lower-Middle Devonian Guanwushan Fm and between the Upper Permian and LowerMiddle Carboniferous in this area. The ages of the missing strata between the Baota and Changjianggou Fm and the Luojaping and Baota Fm are $50 \mathrm{Ma}$ in the Nianziba structure. A weakly compressive tectonic regime from the Caledonian orogeny caused the north segment of the TJS PU to undergo episodic sedimentation-uplift processes during the Early Paleozoic. The relatively stable deposition during the Devonian proceeded with the Lower and Middle Carboniferous strata being developed in a few areas of the northern segment. The Permian Liangshan Fm directly overlies the Devo- nian under the Kuangshanliang-Nianziba structure, which has a hiatus in time of $60 \mathrm{Ma}$ (Figure 8).

The present-day topography of the middle segment of the TJS PU varies slightly. The surface structural features of the middle segment are characterized by two tightly closed anticlinal structures with a linear strike that trends from the northeast to the southwest. The limbs are oriented at $30^{\circ}-$ $60^{\circ}$. The Ordovician-Silurian is not represented in the middle segment of the TJS PU. The missing strata represent a time gap of $110 \mathrm{Ma}$. The siliceous conglomerate at the top of the Changjianggou Fm is an unconformable contact with the overlying Devonian Pingyipu Fm. The stratigraphic characteristics of the Early Paleozoic sequence indicate that the middle segment of the TJS PU was uplifted and denuded without associated deposition during the Caledonian period. When compared to the northern segment, geological mapping has only identified the entire Devonian and Carboniferous sequence in the middle segment of the TJS PU because of the limited thickness of the stratigraphy. The section still indicates stratal development in the Lower and Middle Devonian near Yanmenba. Similar to the northern segment, the 


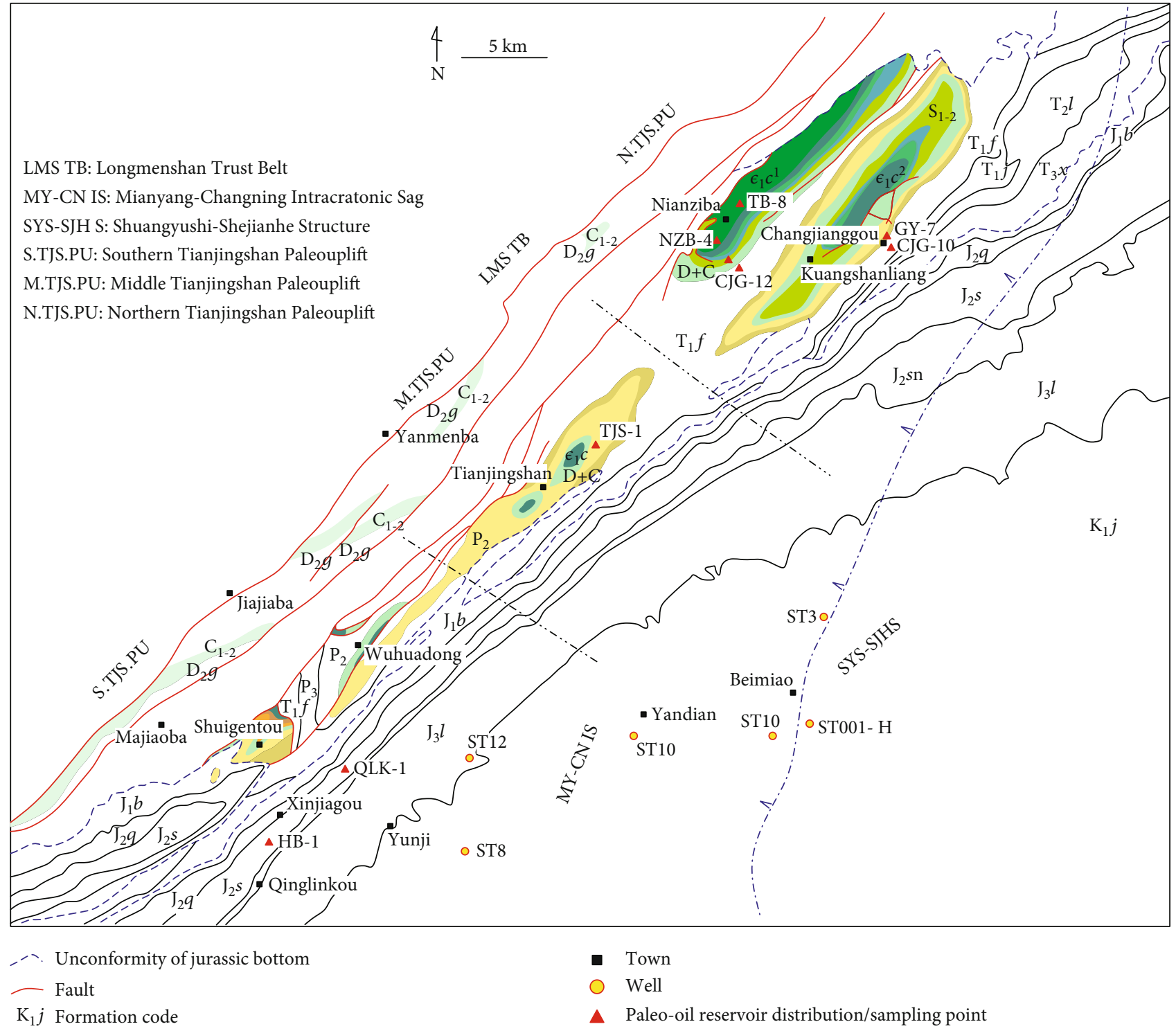

Figure 7: Surface geological characteristics and paleo-oil reservoir distribution in the TJS PU area. The Tianjingshan Paleouplift can be divided into south, middle, and north segment. Nowadays, the Tianjingshan structure belt (Tianjingshan Paleouplift area) is overlapping on the Mianyang-Changning Intracaratonic Sag.

Upper Carboniferous strata are missing in this area. Largescale transgression of the entire basin in the Early Permian caused that unconformities occurred between the Middle Carboniferous and the Middle-Upper Permian in the middle TJS PU. The Triassic strata were subject to deformation through folding during the Mesozoic. The conglomerate of the Lower Jurassic Baitianba Fm overlies the PermianTriassic with an angular unconformable contact.

The southern segment is currently located along Shuigentou-Wuhuadong (Houba-Erlangmiao), which is north of Jiangyou, and appears as an anticline structure that gradually slopes in a southwesterly direction. The surface geology of the southern segment shows a sequence of the middle member from the bottom to the top of the Changjianggou Fm, Lower-Middle Devonian, Lower Carboniferous Zongchanggou Fm, and Permian, respectively. The Paleozoic sequence in the southern segment is also missing the MiddleUpper Cambrian, Ordovician, and Silurian, which indicates that deposition had not occurred in the area for some time owing to uplift and denudation before the Devonian. The discovery of the Devonian during multidrilling at the Shuangyushi structure was followed by the original undivided Lower-Middle Carboniferous strata in the area that was reassigned to the Lower Carboniferous Zongchanggou Fm. The preserved thickness is only $6 \mathrm{~m}$. This indicates that the Carboniferous in the southern segment of the TJS PU is missing $15 \mathrm{Ma}$ and $32 \mathrm{Ma}$ of strata at the top and bottom, respectively.

4.1.3. Early Paleozoic Extension-Compression Transition. The Yunan movement in the Early Cambrian to Early Ordovician caused a sequence of marine conglomerates and sandstones (the Changjianggou Fm) that was deposited on the top of 


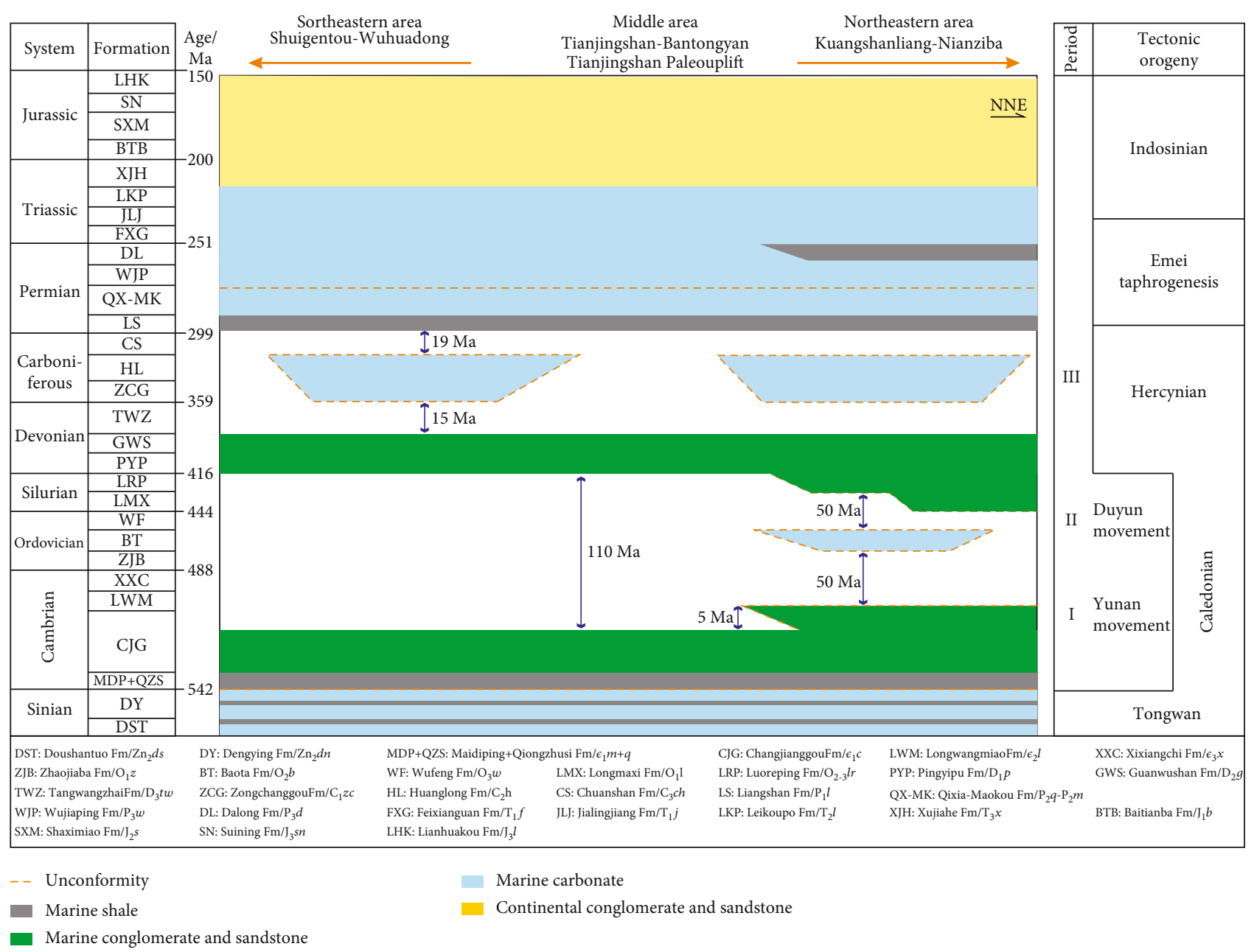

FIGURE 8: Stratigraphic contact of the southern-middle-northern Tianjingshan Paleouplift (TJS PU). Among them, a wide range of Middle Cambrian-Silurian strata is missing, which is mainly in the southern and middle TJS PU. The siliceous conglomerate at the top of the Changjianggou Fm is an unconformable contact with the overlying Devonian Pingyipu Fm, which has a hiatus in time of 110 Ma.

the Lower Cambrian black mudstone in the NSWSCD. However, the Lower Ordovician hiatus may indicate that the Longmenshan ancient land (the TJS PU and the Longmenshan island chain) has been uplifted. The evolution of the TJS PU entered the episodic stage (I) (Figure 9(b)). Therefore, the Caledonian TJS PU must have formed before the Leshan-Longnvsi Paleouplift in central Sichuan.

The Upper Yangtze area reentered a widespread transgressional period at the beginning of the middle Ordovician. The NSWSCD reaccepted stable sediments from sand-mud tidal flats. The transgression intensified in the Middle Ordovician and limestone that was deposited in the northwestern Sichuan Basin. A few studies suggest that during the Late Ordovician and Early Silurian, the Duyun movement, which is evident in southern Guizhou [89], was also essential in the formation of the Caledonian Paleouplift in the Sichuan Basin [90]. Furthermore, the Duyun movement contributed to the development of the Baota Fm karst reservoir in the northwestern Sichuan Basin. The NSWSCD inherited the tectonicsedimentary framework of the Ordovician during the Early Silurian. The sedimentary system appears as a gently dipping homoclinal sequence of carbonate-terrigenous strata [91]. A detailed investigation of the surface geology showed that a set of relatively deep-water black shales that belonged to the shelf facies occurred at the bottom of the Silurian in northern Wangcang [92]. There is also a thin layer of oolitic limestone higher up, which has undergone high-energy sorting and transport [93]. Furthermore, $150 \mathrm{~m}$ of reef deposits was discovered in the Lower-Middle Silurian in the ChaotianGuangyuan area.

The Lower-Middle Silurian is difficult to identify in the Tianjingshan area with sets of gray-green silt-shale interbedded siltstone, which is located in the middle of the NSWSCD. The Luoreping Fm depositional environment was a sand-mud flat to gentle slope or intertidal zone. The Upper Yangtze area had uplifted significantly owing to the Late Caledonian movement (i.e., Guangxi movement) by the end of the Silurian. The Leshan-Longnvsi area in the central Sichuan area was the core of the uplift. Denudation of the Ordovician-Silurian strata provided a large supply of terrestrial detritus for the Devonian sedimentary rocks in the western Sichuan area. The Tianjingshan area underwent discontinuous uplift (Figure 9(c)) during this period. The continuous differential uplifting of the TJS PU area exposed the strata and created unevenly distributed 


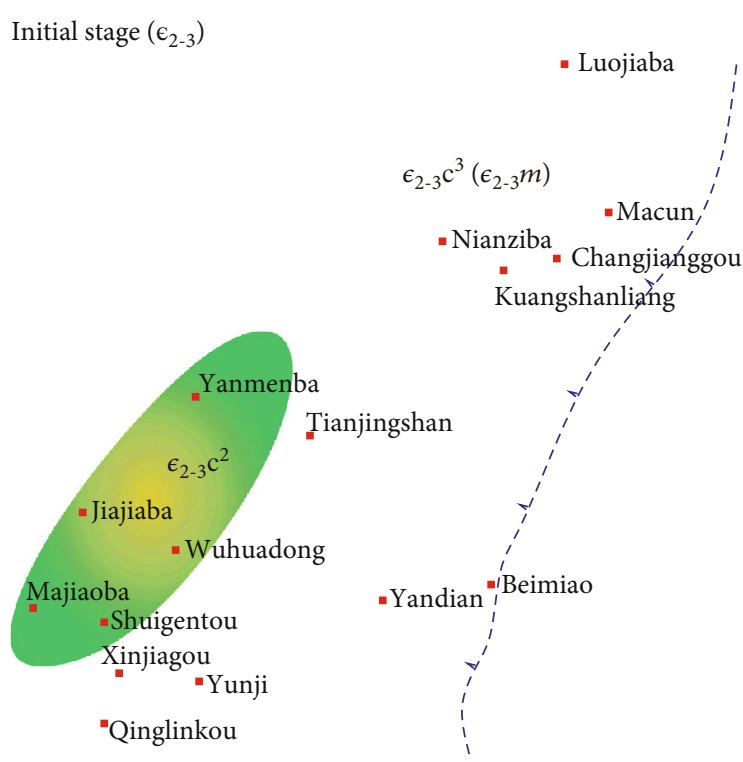

(a)

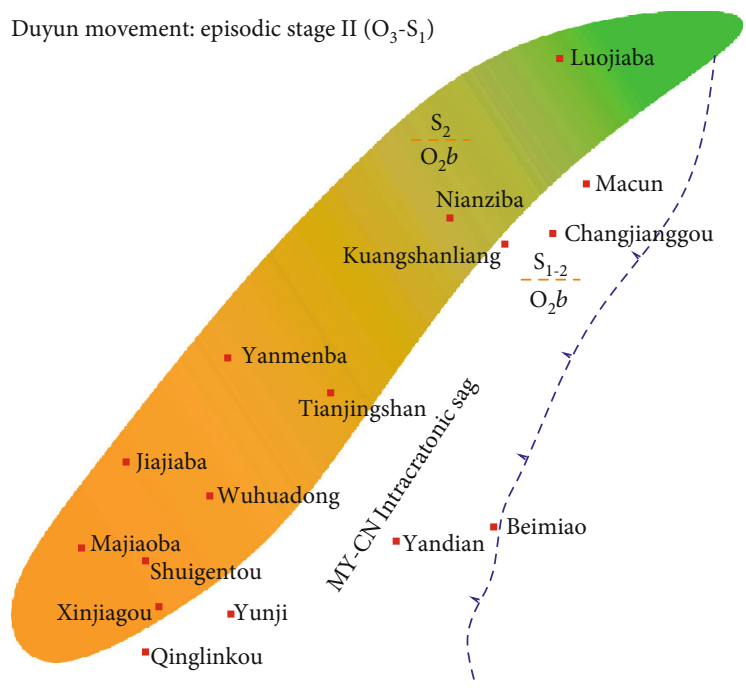

(c)

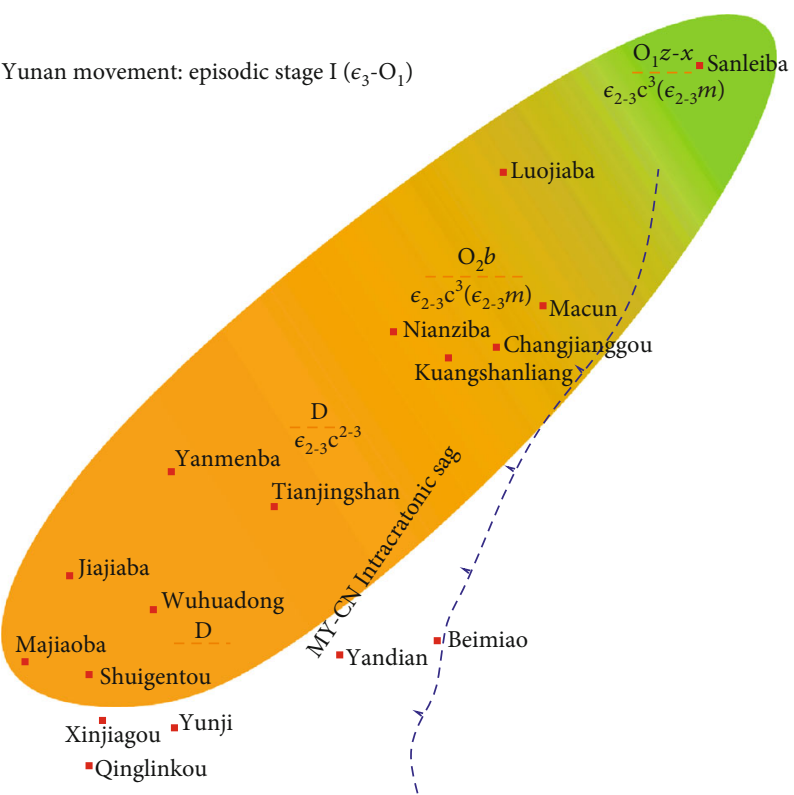

(b)

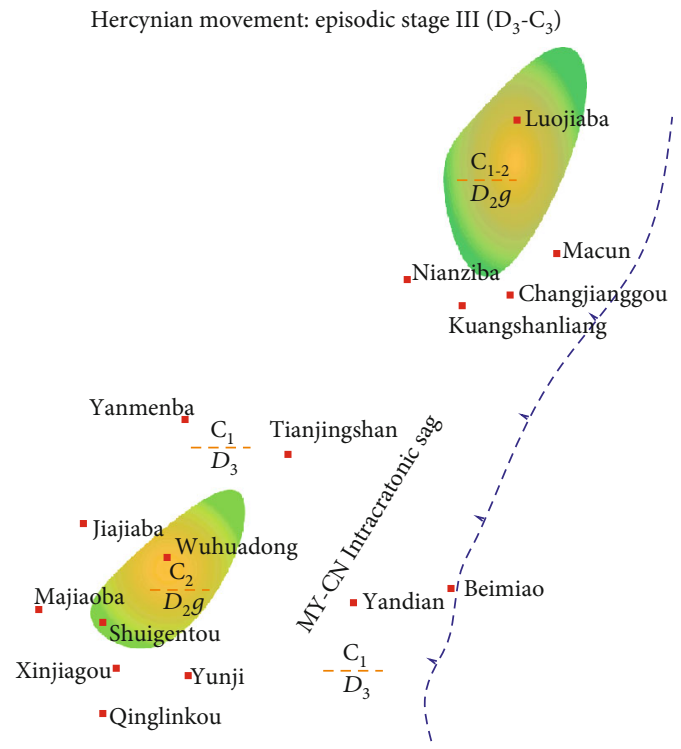

(d)

FIGURE 9: Relationship between the TJS PU and MY-CN IS in different time periods. (a) The prototype of the TJS PU is thought to have formed in the Late Cambrian; (b) corresponding to the Yunan movement, the TJS PU reached its maximum extent; (c) in the Caledonian, the TJS PU was still approximately 10-20 km away from the MY-CN IS; (d) the TJS PU area is reflected and dominated by regression of cyclical sea-level variation in the Hercynian.

unconformities. The current exposure of the KuangshanliangNianziba structure shows that the nodular limestone of the Upper Ordovician Baota Fm has unconformable contact with the lower Changjiangkou Fm and upper Lower Silurian. The significant uplift in the mid-southern segment of the TJS PU caused the Middle-Upper Cambrian, Middle-Upper Ordovician, and Lower Silurian to become nearly absent.

The TJS PU evolved into episode III during the Devonian-Carboniferous Hercynian orogeny. Furthermore, the Tianjingshan area has a deeply buried depositional framework that is consistent with uplift and depression. Devonian lithologies are poorly represented in the paleoup- lift area, with the Middle and Lower Carboniferous overlying the Middle Devonian Guanwushan Fm. A large Devonian sedimentary basin occurs on the western side of the TJS PU. The sand-mud flat depositional environment in an asymmetric NE-oriented rift basin in the TangwangzhaiYangtianwo area represents the center of Devonian subsidence [94]. The NSWSCD transformed into a semienclosed bay environment in the Carboniferous on the western margin of the Yangtze Plate. This was dominated by a limited and semilimited platform to open-platform carbonate sequence [95]. The Carboniferous in the mid-southern segment of the TJS PU is also relatively complete, whereas the 
northern segment lacks Upper Carboniferous deposition. Significant regression in cyclical sea-level variations is indicated in the TJS PU area from the Middle Carboniferous Huanglong Fm to the Upper Carboniferous Chuanshan Fm (Figure 9(d)).

The Paleozoic stratigraphic contacts indicate that the tectonic core of the TJS PU migrated from south to north. The early core of the paleouplift was approximately located in the Shuigentou-Tianjingshan-Bantongyan area of the midsouthern segment. A later increase in uplift and denudation amplitude in the northern segment caused that the structural high moved from the mid-southern to the northern segment. The TJS PU and the MY-CN IS overlapped laterally. The area of the TJS PU was relatively larger in the Late Cambrian and Early Ordovician, and Late Ordovician and Early Silurian of episodes I and II, respectively. The Nianziba-Kuangshanliang area in the northern segment overlapped vertically onto the intracratonic sag. The core of the paleouplift was only approximately $10-20 \mathrm{~km}$ away from scarp I on the eastern side of the MY-CN IS during multistage sea-level rise and fall processes (Figure 9). The Changjiangkou and Pingyipu Fm in the paleouplift area remained on a regional high until the Middle-Late Triassic. This is the optimal accumulation area for early generation oil and gas that is derived from highquality Cambrian source rocks in the northern segment of the MY-CN IS. The formation and structural relationship of the TJS PU with the MY-CN IS led to the development of the intracratonic sag, paleo-uplift complex, and joint model that controls the early accumulation of oil and gas in the NSWSCD. The northern segment of the MY-CN has controlled the development of high-quality source rocks of the Lower Cambrian Maidiping and Qiongzhusi Fm. However, the evolution of the paleouplift coincided spatiotemporally with the superior source rocks. The source rocks and reservoir characteristics in the NSWSCD provided the optimal conditions for hydrocarbon accumulation in the region.

\subsection{The Multistyle and Stage Hydrocarbon Accumulation Characteristics under Complex Geological Background}

4.2.1. Deeply Buried-Strong Uplift Characteristics and Oil-Gas Zoning. Studies of the Dengying Fm-Longwangmiao Fm gas reservoirs (i.e., the Gaoshiti-Moxi structure in the middle Sichuan Basin) have realized the importance of the preservation conditions, which were concluded as four-center accumulation processes of original gas generation centers (paleo-oil reservoirs), the transition of gas storage centers, and the current gas-holding centers (present gas reservoirs) [96-98].

Two important faults were evolved at the junction of the NSWSCD and the LMS TB, which are the Majiaoba fault (MJB F) and the frontal hidden fault (i.e., No. 1 fault), after the Late Triassic. The Majiaoba fault is a zone that comprises of several thrust faults and single faults that often have limited extension. This is the boundary fault between the LMS TB and the NSWSCD. The Majiaoba fault mainly developed along the clasolite of the Upper Triassic Xujiahe Fm. The area to the west of the fault is mainly composed of pre-Jurassic strata. The oil and gas preservation conditions have been destroyed completely after undergoing extreme deformation.
The east of the fault is mainly composed of Jurassic and younger strata, which include minor deformation. The No. 1 fault is predominantly buried and primarily developed together with the continental clasolite formations from the Jurassic. The No. 1 fault is also known as the GuangyuanDayi (hidden) Fault. The No. 1 fault developed inside the Upper Yangtze block, which is the extended result of thrust movement from the LMS TB to the foreland. The frontal and deformation zone of the NSWSCD remained involved in the deformation to varying degrees. The angle of the dip of the strata decreases rapidly in the easternmost No. 1 fault area.

When the NSWSCD is considered, the No. 1 fault is also a boundary fault that is characterized by deeply buried and strong uplift (Figure 10). According to the main structural events after the Late Triassic, the formation and evolution of the No. 1 fault have been an important influence on the early accumulation effect of the paleo-oil reservoir in the TJS PU. The No. 1 fault also divided the oil-gas zone after the Late Triassic. The current Middle Permian top structural map of the NSWSCD shows that the two subzones have typical burial depth differences owing to the influence of the thrust belt on extension and deformation. The burial depth of the Paleozoic (Cambrian-Middle Permian) in the hanging-wall of the No. 1 fault (i.e., frontal deformation zone in the NSWSCD) is generally maintained at $2500-4000 \mathrm{~m}$ after being affected by the rapid uplift and erosion processes of the LMS TB after the Late Triassic. Numerous residual paleo-oil reservoirs dominate the surface. The evolution process of the paleo-oil reservoir system in the Tianjingshan Tectonic Belt (frontal deformation zone) of the NSWSCD has led to the following formations: first, the Early Tianjingshan Paleouplift oil reservoir (Dengying Fm-Changjianggou Fm-Lower Devonian); second, the adjustment and reconstruction of the subdamaged secondary oil reservoir (Qixia Fm-Feixianguan Fm) with multistage and lateral-vertical migration; third, the complete destruction of the residual oil reservoirs (Upper Cambrian solid bitumen-Jurassic tar sand) in the Himalayan period (Figure 11). Therefore, only the hydrocarbon accumulation process from the paleo-oil reservoirs has been maintained during the destruction of the paleo-oil reservoirs in the frontal deformation zone of NSWSCD.

\subsubsection{Multistyle and Stage Characteristics of Deep} Hydrocarbon Accumulation. Based on the inheritance and innovation of source control theory, which has a multisource supply of high-quality Cambrian source rock as the core, the contrasting relationship between cap strength and trap closure height are the main factors that control oil and gas distribution. The superimposed basin is an important attribute of the Sichuan Basin. The oil and gas accumulation process in the NSWSCD of the Sichuan superimposed basin includes the following processes. First, the coupling process of paleooil reservoir formation and destruction in the frontal deformation zone, gas reservoir formation, and adjustment processes in the target deeply buried Upper Proterozoic Sinian Dengying Fm. Second, the current exploration and development of the Upper Paleozoic Middle Permian Qixia Fm. 


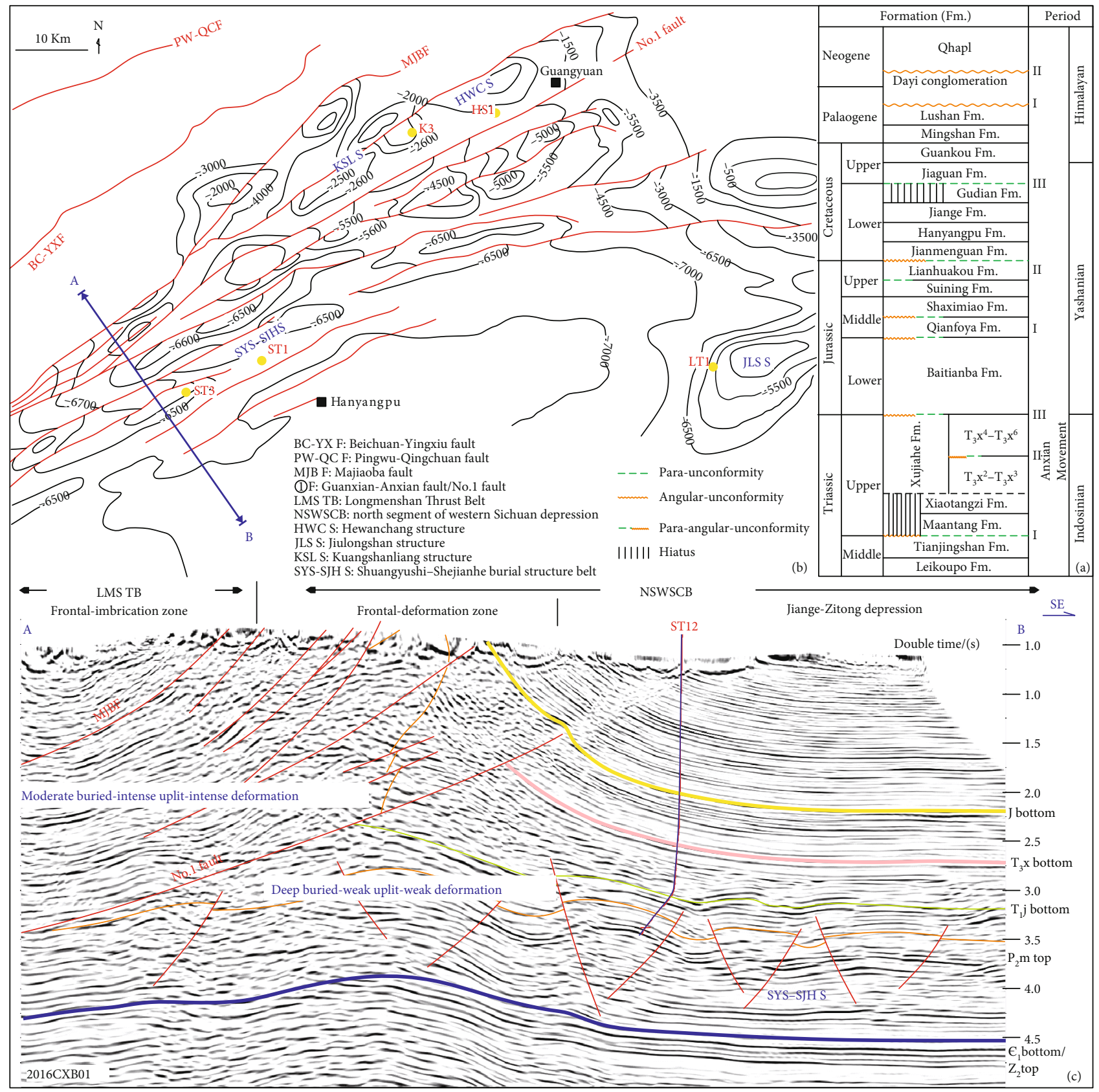

Figure 10: (a) The NSWSCD has experienced three stages (eight periods) of tectonic movements since the Late Triassic. (b) The structural map (Middle Permian top) showing that the NSWSCD has developed a series of subsurface structures (HWC S, SYS-SJH S, and JLS S). (c) NW-SE section shows that the No. 1 fault has divided the NSWSCD into the frontal and deformation zone, and the Jiange-Zitong depression, which has different structural histories after the Late Triassic.

Third, other oil and gas-bearing processes used for reservoir formation.

(1) Multistyle Characteristics. The deep marine hydrocarbon accumulation in the NSWSCD can be divided into two categories. The first is the primary oil-gas reservoir model, which includes the Lower Cambrian source rocks that are mature enough for hydrocarbon expulsion. This has the migration of the side generation to the side of the reservoir (Dengying Fm), upper generation to the lower reservoir (Dengying Fm), or lower generation to the upper reservoir (the overly- ing Longwangmiao Fm, the Qixia-Makou Fm, and other paleo-oil reservoirs). The paleo-oil reservoirs were cracked in situ in the later stages. Typical thermally cracked bitumen allows for the paleo-oil reservoirs that formed the current gas reservoir. The primary reservoir and primary gas reservoir model is located near the eastern boundary of the MY-CN IS and the NSWSCD. This includes scarp (I) of the deeply buried Shuangyushi-Shejianhe structure and scarp II of the Langzhong-Jiulongshan-Yuanba area, which has a pivotal role in oil and gas exploration in the Dengying, Longwangmiao, and Qixia-Maokou Formations. 


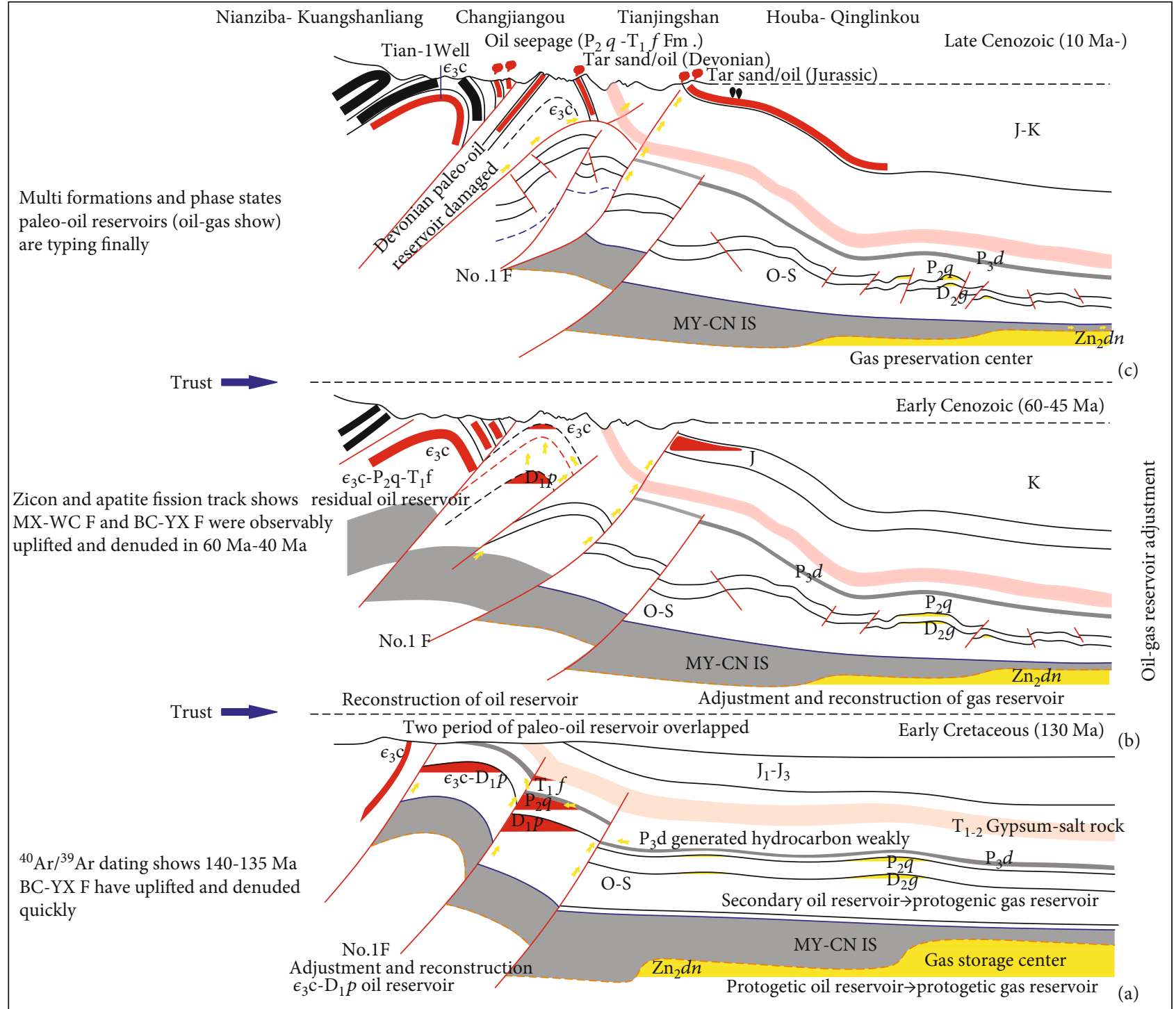

FIGURE 11: Model of deeply buried hydrocarbon accumulation and oil-gas zoning in the NSWSCD. (a) With a complete thermal cracking process, the gas storage center may have formed in the Dengying Fm at the eastern boundary of the MY-CN IS. (b) The oil reservoir and deeply buried gas reservoir were adjusted and reconstructed continuously on both sides of the No. 1 fault. (c) Paleo-oil reservoir (oil seeps, tar sand, and bitumen dykes) and deeply buried gas reservoirs formed from the Late Cenozoic.

The second category is the secondary reservoir and the primary gas reservoir model. The weak adjustment and transformation of local uplift, denudation, and thrusting causes the primary paleo-oil reservoir to mainly consist of the Dengying Fm that was partially damaged during the Indosinian period. The partial paleo-oil reservoirs had migrated into the upper Guanwushan Fm, Qixia-Makou Fm, and Feixianguan Fm, which has relatively shallow burial depths. This was achieved through secondary migration that uses the fracture-to-fracture system to form the secondary reservoirs. If later tectonic activity is relatively stable, the secondary reservoir will not be damaged again. The bitumen in the reservoir will undergo thermal cracking with oil cracked in situ to form a primary gas reservoir. The rapid and pronounced uplift and denudation process in the YanshanianHishanian period caused the secondary oil reservoirs to be destroyed completely. The crude oil migrated to the shallow surface to form residual paleo-oil reservoirs such as oil seeps, oil sands, heavy oil, and solid bitumen veins. The gas reservoirs of the Guanwushan and Qixia-Maokou Fm in the Shuangyushi-Shejianhe structure belt of the NSWSCD (on the east side of the No. 1 fault) belong to the secondary reservoir and primary gas reservoir model. Notably, the local Permian and Triassic gas reservoirs in the northern part of the NSWSCD may also have individual source rocks within the Dalong Fm source rocks because of the Guangwang, Kaijiang, and Liangping intracratonic sag. Therefore, the Devonian-Permian gas reservoirs in the HewanchangJiulongshan area can be a combination of either primary oil and gas reservoirs or secondary oil and primary gas reservoirs.

(2) Multistage Characteristics. The combination of the multiple unconformities, fault-based migration system, and 

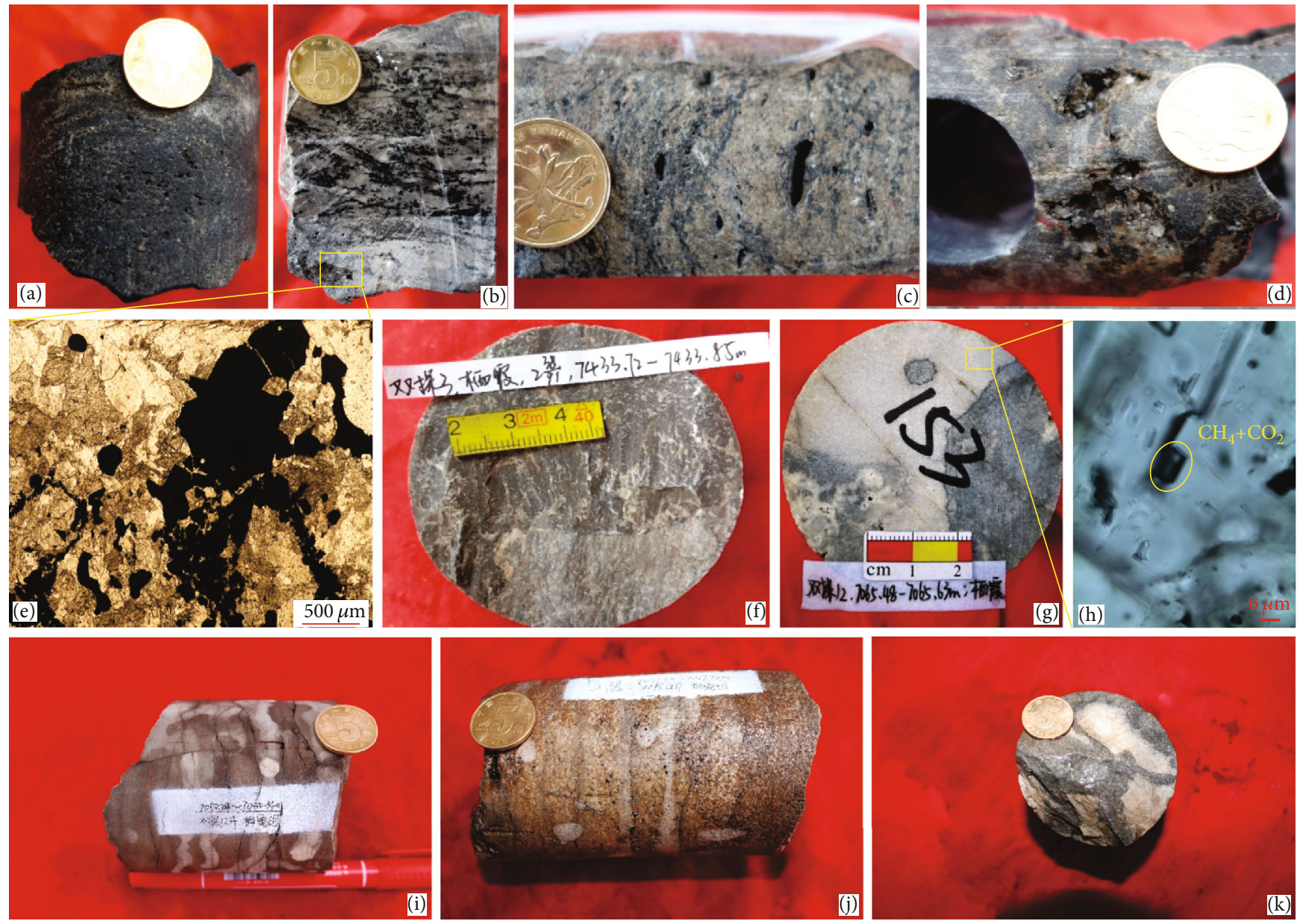

FIGURE 12: Deeply buried reservoir characteristics of the Dengying and Qixia formations. (a) CS-1 well that is located between 8161.07 and $8161.20 \mathrm{~m}$ and consists of algal-laminae stromatolite dolomite $\left(\mathrm{Zn}_{2} d n^{4}\right)$. (b) CS- 1 well that is located between 8162.04 and $8162.15 \mathrm{~m}$ and consists of algal-dolarenite and algal irregular nodule dolomite $\left(\mathrm{Zn}_{2} d n^{4}\right)$. (c) CS-1 well that is located between 8160.29 and $8160.36 \mathrm{~m}$ and consists of karst holes that are formed near the unconformity at the top of the Dengying Fm $\left(\mathrm{Zn}_{2} d n^{4}\right)$. (d) CS-1 well that is located between 8157.96 and $8158.07 \mathrm{~m}$ and consists of karst holes that are formed by strong paleokarst weathering at the top of the Dengying Fm $\left(\mathrm{Zn}_{2} d n^{4}\right)$. (e) CS-1 well that is located between 8157.18 and $8157.34 \mathrm{~m}$ and consists of fine crystalline dolomite with bitumen and saddleshaped dolomite that fills in super large intercrystalline pores and intercrystalline dissolved pores. The traces of bitumen that are notably disturbed and broken $\left(\mathrm{Zn}_{2} d n^{4}\right)$ into $5 \times 10$ m pieces. (f) ST-3 well, which is located between 7433.72 and 7433.85 m, consists of dolomitic leopard limestone $\left(\mathrm{P}_{2} q\right)$. (g) ST-12 well that is located between 7065.48 and $7065.63 \mathrm{~m}$ and consists of the bedrock is micrite. Gray leopard dolomicrite that is formed after partial dolomitization $\left(\mathrm{P}_{2} \mathrm{q}\right)$. (h) ST-12 well that has characteristics of methane-bearing inclusion in coarse-grain dolomite of the Qixia Fm. (i) ST-12 well that is located between 7050.24 and $7050.34 \mathrm{~m}$ and consists of gray micrite with developed fractures $\left(\mathrm{P}_{2} q^{2}\right)$. (j) ST-12 well that is located between 7057.50 and $7057.72 \mathrm{~m}$ and consists of micrite with corrosion pores and a large amount of bitumen infill. (k) ST-12 well that is located between 7059.22 and $7059.28 \mathrm{~m}$ and consists of two-stage dolomitization, the early stage is dolomicrite and later recrystallized to form gray-white, medium-coarse, and grained dolomite $\left(\mathrm{P}_{2} q^{2}\right)$.

inclusion homogenization temperature data (Dengying and Qixia formations) corresponds to structural deformation and evolution periods. Furthermore, this combination led to the constraints of thermal burial histories that were used to establish deep marine hydrocarbon accumulation processes in the NSWSCD. Early burial and recrystallization processes created first-generation dolomicrites with relatively rare microbial calcic-shell concretions in the Dengying Fm. The pores of the Dengying Fm microbial dolomite are well developed and filled with fourth-generation saddle-shaped, coarse-grained dolomite, and a small amount of mesocrystalline dolomite in the two ultradeep samples of the CS-1 well. According to the observation of the mineral generation rela- tionship between the pores and bitumen infills in the Dengying Fm, the filling sequence can be expressed as firstgeneration dolomicrite, second-generation mesocrystalline dolomite, third-generation bitumen, and fourth-generation saddle-shaped dolomite (Figures 12(b) and 12(e)). The fourth-generation dolomite of the Dengying Fm in the NSWSCD is more common, which primarily occurs as saddle-shaped monocrystalline dolomite. Bitumen is a typical result of the thermal cracking of oil and is formed in the gas window during deeply buried. Fluid inclusions in the saddle-shaped dolomite are relatively abundant, distributed in the cleavage, and the growth annulus of the crystals. Given the association with third-generation bitumen, the fourth- 


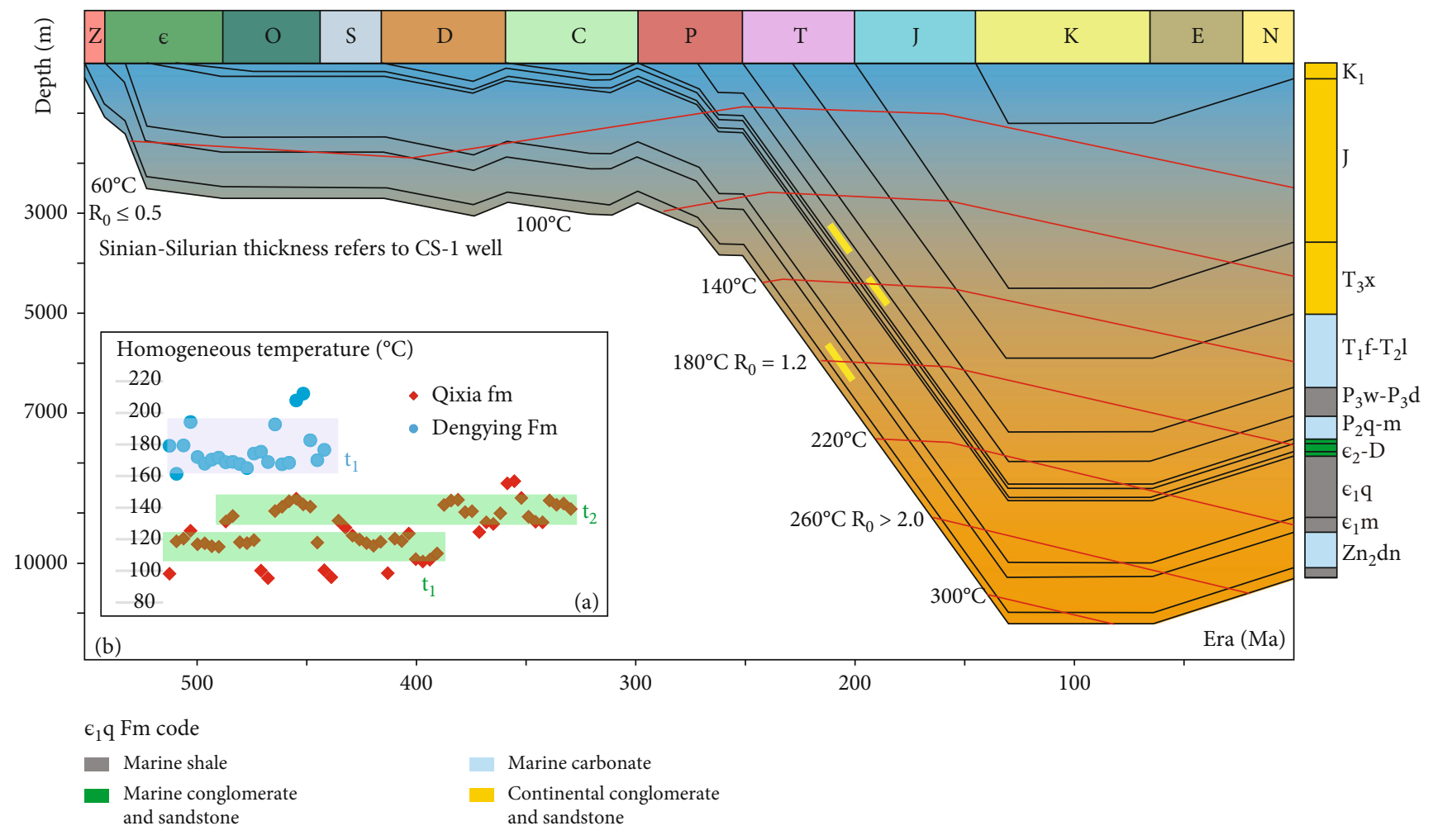

Figure 13: (a) The inclusion $\mathrm{T}_{\mathrm{h}}$ of the Dengying Fm is $167-176^{\circ} \mathrm{C}$. The Qixia Fm has two sets of peaks at $115-125^{\circ} \mathrm{C}$ and $135-145^{\circ} \mathrm{C}$, respectively. (b) Thermal burial evolution that is combined with $R_{o}$ and fluid inclusion characteristics indicates that the gas (oil-cracked) charging period of the NSWSCD that mainly occurred in the Middle-Late Triassic to Early Jurassic.

generation dolomite is the primary target for inclusion temperature measurement. The homogenization temperature recorded by the fluid inclusions in the Dengying Fm is set at $167-176^{\circ} \mathrm{C}$. According to the thermal burial model, the top of the Dengying Fm is approximately $5200 \mathrm{~m}$ deep in the Lower-Middle Triassic. The fluids were consistent over a cracking period of the previously charged oil in the Sinian Dengying Fm.

The abundance of inclusions in the deeply buried Qixia Fm is relatively limited from the ST-12 well in the NSWSCD. According to the statistical observation of the core, the edge of the hole in the Qixia Fm contains either first-generation dolomicrite, second-generation bitumen, third-generation saddle-shaped dolomite, or third-generation mesocrystalline dolomite (Figure 12(h)). The second-generation bitumen is a typical thermally cracked bitumen. The filling order shows that the saddle-shaped and mesocrystalline dolomite occurred later than the thermally cracked bitumen, which indicated that the fluid filling in this period occurred after the gas generation window. The dolomite reservoirs of the Qixia Fm have mainly powdered crystal dolomite in the (pre) oil generation window. The inclusions in this period are very small, with a lack of tawny oil inclusions. The primary or secondary oil reservoirs are relatively weakly charged in the Qixia Fm. The minerals formed after the gas generation window were mainly either coarse-grained dolomite or saddle-shaped dolomite.
Raman spectroscopy analysis of fluid inclusions in coarse-grained dolomite of the Qixia Fm shows that some gaseous phases of some of the $\mathrm{SAH}$ aqueous inclusions have noticeable characteristic $\mathrm{CH}_{4}$ peaks, which indicates that these hydrocarbon inclusions should be pure liquid methane-bearing. The dolomite with coexisting SAH aqueous and methane-bearing inclusions was selected to measure the homogenization temperatures and to obtain density and salinity values. The ST-12 well (burial depth in the Qixia Fm ranging 7061.83-7083.50 m) has 58 inclusions in the 6 samples (CXB01-CXB06), has homogenization temperatures ranging $95.4-156.8^{\circ} \mathrm{C}$, and has freezing point temperatures from -9.6 to $-5^{\circ} \mathrm{C}$. The calculated salinity and the density range are $7.86 \%-13.51 \%$ and $0.99-1.03 \mathrm{~g} / \mathrm{cm}^{3}$, respectively. The inclusions of the Qixia Fm have two sets of peaks at $115-125^{\circ} \mathrm{C}$ and $135-145^{\circ} \mathrm{C}$ (Figure 13). This can represent the main oil and gas filling process in the Middle-Late Triassic and Late Triassic to Early Jurassic (Figure 13). Subsequently, a temperature range of $115-125^{\circ} \mathrm{C}$ approximately corresponds to vertical gas charging that originated from underlying strata (probably the Dengying Fm). Additionally, $135-145^{\circ} \mathrm{C}$ can represent the gas generation (oil-cracking) window of the secondary (or protogenic) oil reservoir.

4.2.3. Four-Center Accumulation Processes of Deeply Buried Dengying and Qixia Fm. Currently, the deep marine hydrocarbon system in the NSWSCD is controlled by the composite action of the intracratonic sag, paleouplift, and basin- 


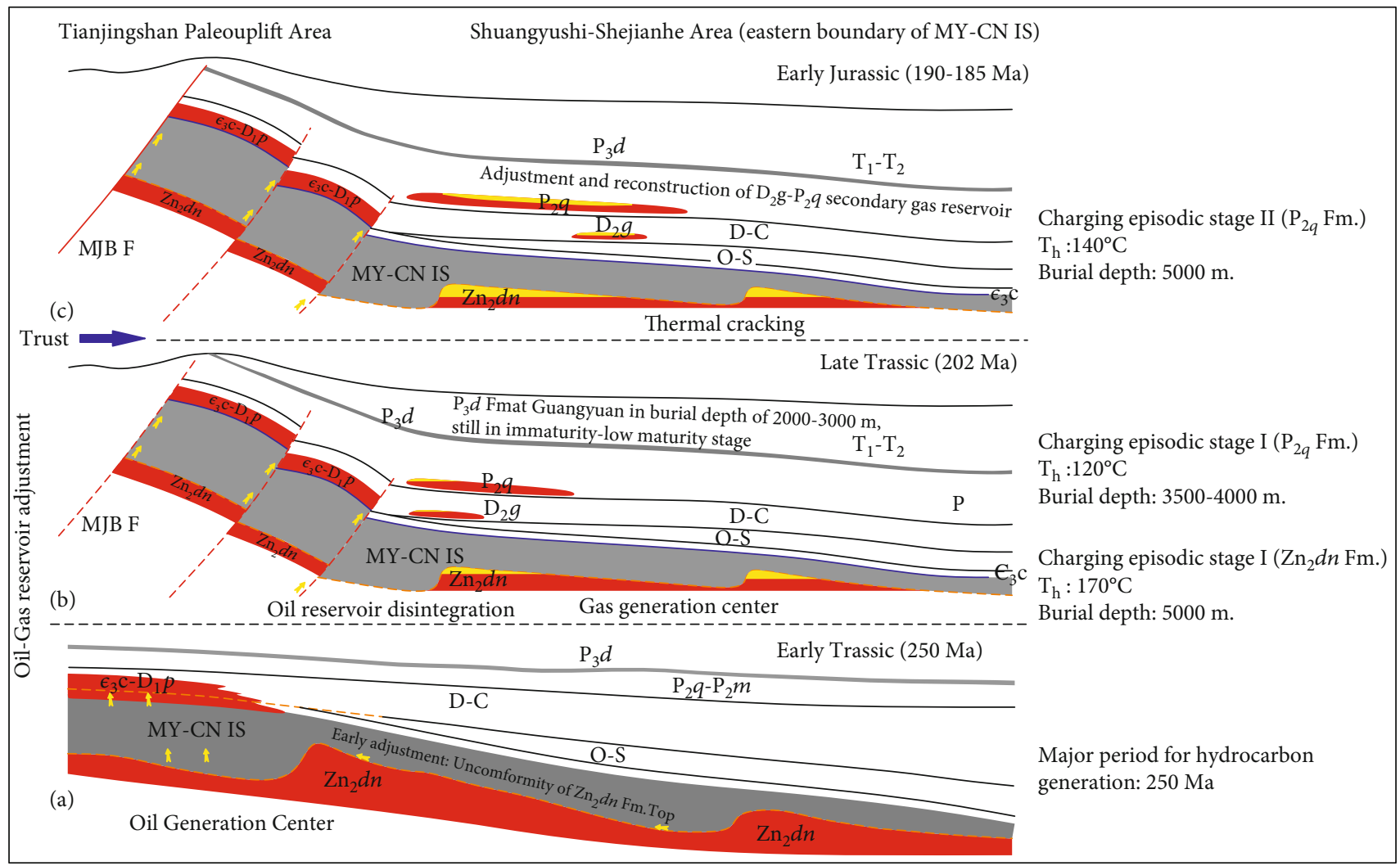

FIGURE 14: The early formation and evolution processes of the paleo-oil reservoir in the Tianjingshan Paleouplift (TJS PU) area. (a) The Early Triassic shows that the TJS PU area is still at the structural high for oil accumulation in the NSWSCD. (b) The oil reservoir disintegrating (Dengying Fm) in the Late Triassic shows that the gas generation center formed gradually in the Shuangshi-Shejianhe area. (c) A burial depth of $5000 \mathrm{~m}$ and temperature of $140^{\circ} \mathrm{C}$ shows that the second gas charging of the Qixia Fm was coupled with gas reservoir adjustment and reconstruction in the Early Jurassic.

mountain structure. Initial uplift and denudation occurred in the Tianjingshan area in the middle of the Early Cambrian. The formation of the TJS PU eventually caused the generated oil to migrate to the high part of the paleouplift area, which formed a paleo-oil reservoir under suitable trap conditions. The TJS PU area controlled early protogenetic hydrocarbon migration, accumulation, and distribution in the Dengying Fm and Cambrian-Devonian before the Triassic (Figure 14). The Shuangyushi-Shejianhe area and the east platform margin of the MY-CN IS (to the east of the No. 1 fault) were the enrichment zones for the adjusted paleo-oil reservoirs during the Indosinian period. Furthermore, these represent the best preservation conditions for the transformation from gas generation to gas storage center (Figure 11(a)).

The main body of the WSCD was shaped gradually after the Early Cretaceous. The rapid settlement of the western Sichuan foreland basin has increased the burial depth of the deep marine strata below the Lower Triassic in the footwall of the No. 1 fault. The construction of the margin-plate and basin-mountain system created the burial depths of the Shuangyushi-Shejianhe structure and the eastern platform margin of the MY-CN IS area (east of the No. 1 fault), which are greater than $8000 \mathrm{~m}$. The paleo-oil reservoirs were completely cracked to form the paleo-gas reservoir during deep burial and high-temperature processes. The Dengying, Canglangpu, Guanwushan, and Qixia Fm have visible bitumen infills in the Shuangyushi-Shejianhe structural belt. Furthermore, the east side of the northern segment of the MY$\mathrm{CN}$ IS is an oil-cracked gas reservoir. This process has facilitated the adjustment from gas generation to gas storage center (Figure 11(a)). The margin-plate and basin-mountain boundary of the WSCB has an important influence on the preservation of deep marine hydrocarbons and the final distribution of current gas reservoirs. Uplift since the late Cretaceous-Cenozoic has had negligible impact on the deep marine strata to the east of the No. 1 fault in the NSWSCD. The final shape of the Shuangyushi-Shejianhe structure belt is the resultant gas-rich region, which has a final transition process from gas storage to a gas preservation center (Figure 11(c)).

\section{Conclusions}

(1) This study analyzes the oil-to-source correlation of Sinian-Jurassic multilayered paleo-oil reservoirs in the Tianjingshan Tectonic Belt. Notably, the paleooil reservoirs are the main source of Cambrian organic matter-rich black shale, which established the concept of the Tianjingshan paleo-oil reservoir system 
(2) The Early Paleozoic Mianyang-Changning intracratonic sag and the Tianjingshan Paleouplift units have a laterally superimposed relationship. The reservoirforming combination of high-quality source rocks and dominant hydrocarbon charging area developed in the northern segment of the western Sichuan Basin. This shows the early accumulation effects of regional marine petroleum on tectonic-controlled conditions

(3) The northern segment of the western Sichuan depression that was affected by multistage tectonic events, recorded a complex tectonic history with strong uplift and deeply buried since the Late Triassic. The formation and evolution of the No. 1 fault have been an important criterion for the division of the oil-gas zonation in the Tianjingshan Paleouplift area

(4) The preservation conditions of the foreland frontaldeformation zone (i.e., hanging-wall of the No. 1 fault) have been entirely destroyed. Furthermore, only a hydrocarbon accumulation process of paleooil reservoir destruction remains. The deeply buried Dengying and Qixia formations to the east of the No. 1 fault have the four-center accumulation conditions, which include the hydrocarbon generation center, gas generation center, gas storage center, and gas preservation center. The superdeep Dengying Fm has necessary petroleum geologic conditions for the discovery of a large-scale gas reservoir in the NSWSCD

\section{Data Availability}

Some or all data, models, or codes used during the study were provided by a third party. Direct requests for these materials may be made to the provider as indicated in Acknowledgments.

\section{Conflicts of Interest}

The authors declare that they have no conflicts of interest.

\section{Acknowledgments}

This work was supported by the National Natural Science Foundation of China (No. 441572111 and No. 41972150). We are grateful to the editors and experts for their constructive comments.

\section{References}

[1] S. G. Liu, B. Deng, Z. W. Li, and W. Sun, "The texture of sedimentary basin-orogenic belt system and its influence on oil/gas distribution:a case study from Sichuan basin," Acta Petrologica Sinica, vol. 27, no. 3, pp. 621-635, 2011.

[2] J. Q. Wang, "Relationship between tectonic evolution and the foreland hydrocarbon in the Longmen Mountains," Acta Geosicientia Sinica, vol. 15, no. 3/4, pp. 167-179, 1994.
[3] K. L. Deng, "Indosinian progressive deformation and its chronogenesis in Longmengshan structural belt," Oil \& Gas Geology, vol. 28, no. 4, pp. 485-490, 2007.

[4] Z. W. Li, S. G. Liu, J. Lin, C. Tang, B. Deng, and W. Sun, "Structural configuration and its genetic mechanism of the west Sichuan depression in China," Journal of Chengdu University of Technology (Science \& Technology Edition), vol. 36, no. 6, pp. 645-653, 2009.

[5] S. G. Liu, Z. W. Li, J. X. Cao et al., "4-D textural and structural characteristics of Longmen intracontinental composite orogenic belt,southwest China," Chinese Journal of Geology, vol. 44, no. 4, pp. 1151-1180, 2009.

[6] S. G. Liu, The Formation and Evolution of Longmenshan Thrust Zone and West Sichuan Foreland Basin, Press of Chengdu Uiversity of Science and Technology University, Chengdu, 1993.

[7] Z. W. Guo, K. L. Deng, and Y. H. Han, The Formation and Development of Sichuan Basin, Geological Publishing House, Beijing, 1996.

[8] W. H. Song, "On nappe structure at northern sector of Longmen Mountain and its oil and gas prospects," Natural Gas Indusdry, vol. 9, no. 3, pp. 12-16, 1989.

[9] C. G. Tong and S. Q. Hu, "Prospective value of oil and gas in the foothill belt of the north Longmen Mountains," Journal of Chengdu University of Technology, vol. 2, pp. 1-8, 1997.

[10] S. G. Liu, W. Sun, Z. L. Luo et al., "Xingkai taphrogenesis and petroleum exploration from upper Sinian to Cambrian strata in Sichuan Basin, China," Journal of Chengdu University of Technology (Science \& Technology Edition), vol. 40, no. 5, pp. 511-520, 2013.

[11] Y. Zhong, Y. L. Li, X. B. Zhang et al., "Features of extensional structures in pre-Sinian to Cambrian strata, Sichuan Basin, China," Journal of Chengdu University of Technology (Science \& Technology Edition), vol. 40, no. 5, pp. 498-510, 2013.

[12] X. Liang, S. G. Liu, Q. W. Mo et al., "The characteristics of marine hydrocarbon accumulation and its exploration prospects in the northern section of western Sichuan depression, China," Journal of Chengdu University of Technology (Science \& Technology Edition), vol. 45, no. 1, pp. 53-67, 2018.

[13] Z. W. Li, H. D. Chen, S. G. Liu, M. C. Hou, and B. Deng, "Differential uplift driven by thrusting and its lateral variation along the Longmenshan belt, western Sichuan, China: evidence from fission track thermochronology," Chinese Journal of Geology (Scientia Geologica Sinica), vol. 45, no. 4, pp. 944968, 2010.

[14] Z. Li, S. Liu, H. Chen, D. Sun, J. Lin, and C. Tang, "Structural superimposition and conjunction and its effects on hydrocarbon accumulation in the western Sichuan depression," Petroleum Exploration and Development, vol. 38, no. 5, pp. 538551, 2011.

[15] M.-F. Zhou, D.-P. Yan, A. K. Kennedy, Y. Li, and J. Ding, "SHRIMP U-Pb zircon geochronological and geochemical evidence for Neoproterozoic arc-magmatism along the western margin of the Yangtze block, south China," Earth and Planetary Science Letters, vol. 196, no. 1-2, pp. 51-67, 2002.

[16] J. H. Zhao and M. F. Zhou, "Neoproterozoic adakitic plutons in the northern margin of the Yangtze block, China: partial melting of a thickened lower crust and implications for secular crustal evolution," Lithos, vol. 104, no. 1-4, pp. 231-248, 2008.

[17] V. E. Andrusevich, M. H. Engel, J. E. Zumberge, and L. A. Brothers, "Secular, episodic changes in stable carbon isotope 
composition of crude oils," Chemical Geology, vol. 152, pp. 5972, 1998.

[18] X. H. Li, "U-Pb zircon ages of granites from the southern margin of the Yangtze block: timing of Neoproterozoic Jinning: orogeny in SE China and implications for Rodinia assembly," Precambrian Research, vol. 97, no. 1-2, pp. 43-57, 1999.

[19] J. Wang and Z. X. Li, "History of Neoproterozoic rift basins in south China: implications for Rodinia break-up," Precambrian Research, vol. 122, no. 1-4, pp. 141-158, 2003.

[20] Z. L. Luo, "A discussion of Taphrogenesis and hydrocarbon distribution," Acta Geoscientica Siniaca, vol. 3, pp. 93-101, 1984.

[21] X. Z. Cui, X. S. Jiang, J. Wang et al., "Filling sequence and evolution model of the Neoproterozoic rift basin in Central Yunnan Province, south China: response to the breakup of Rodinia supercontinent," Acta Sedimentologica Sinica, vol. 32, no. 3, pp. 399-409, 2014.

[22] Z. D. Gu and Z. C. Wang, "The discovery of Neoproterozoic extensional structures and its significance for gas exploration in the Central Sichuan Block, Sichuan Basin, south China," Scientia Sinica (Terrae), vol. 44, no. 10, pp. 2210-2220, 2014.

[23] H. F. Liu, J. M. Li, X. Q. Li, L. Q. Liu, X. J. Li, and S. H. Hu, "Evolution of cratonic basins and carbonate-evaporite sedimentary sequence hydrocarbon systems in China," Journal of Geosciences, vol. 20, no. 1, pp. 1-18, 2016.

[24] Q. Yu, C. L. Mu, H. Q. Zhang, Q. Y. Tan, X. S. Xu, and J. F. Yan, "Sedimentary evolution and reservoir distribution of northern upper Yangtze plate in Sinicn-Early Paleozoic," Acta Petrologica Sinica, vol. 27, no. 3, pp. 672-680, 2011.

[25] S. G. Liu, W. Sun, Y. Zhong et al., "Evolutionary episodes and their characteristics within the Sichuan marine craton basin during Phanerozoic Eon," Acta Petrologica Sinica, vol. 33, no. 4, pp. 1058-1072, 2017.

[26] J. M. Song, P. Luo, S. G. Liu et al., “The deposition and reservoir characteristics of Dengying formation in western Sichuan Basin, China," Journal of Chengdu University of Technology (Science \& Technology Edition), vol. 45, no. 1, pp. 27-44, 2018.

[27] M. C. Hou, F. C. Xing, S. L. Xu et al., "Paleogeographic patterns of $\mathrm{E}-\mathrm{C}$ transition period in the upper Yangtze and the geodynamic mechanism," Acta Sedimentologica Sinica, vol. 35, no. 5, pp. 902-917, 2017.

[28] J. J. Liu, W. Li, B. M. Zhang et al., "Sedimentary palaeogeography of the Sinian in upper Yangtze region," Journal of Palaeogeography, vol. 17, no. 6, pp. 735-753, 2015.

[29] H. Zhou, W. Li, B. M. Zhang et al., "Formation and evolution of upper Sinian to lower Cambrian intraplatformal basin in Sichuan Basin," ActaPetroleiSinica, vol. 36, no. 3, pp. 310323, 2015.

[30] F. C. Xing, M. C. Hou, L. B. Lin, S. L. Xu, and H. R. Hu, “The records and its dynamic genesis discussion of tectonic movement during the late Sinian and the early Cambrian of Sichuan Basin," Earth Science Frontiers, vol. 22, no. 1, pp. 115-125, 2015.

[31] J. H. Du, C. N. Zou, C. C. Xu et al., "Theoretical and technical innovations in strategic discovery of a giant gas field in Cambrian Longwangmiao Formation of central Sichuan paleouplift, Sichuan Basin," Petroleum Exploration and Development, vol. 41, pp. 268-277, 2014.

[32] C. N. Zou, J. H. Du, C. C. Xu et al., "Formation, distribution, resource potential and discovery of the Sinian-Cambrian giant gas field, Sichuan Basin, SW China," Petroleum Exploration and Development, vol. 41, pp. 278-293, 2014.

[33] G. Q. Wei, W. Yang, J. H. Du et al., "Geological characteristics of the Sinian-Early Cambrian intracratonic rift, Sichuan Basin," Natural Gas Industry, vol. 35, no. 1, pp. 24-35, 2015.

[34] S. G. Liu, Y. G. Wang, W. Sun et al., "Control of intracratonic sags on the hydrocarbon accumulations in the marine strata across the Sichuan Basin, China," Journal of Chengdu University of Technology (Science \& Technology Edition), vol. 43, pp. 1-23, 2016.

[35] S. Q. Xu, Q. Zeng, D. H. Tang, and G. R. Zhang, “Analysis on reservoir forming conditions of Houba oil sands in Jiangyou area," Natural Gas Exploration \& Development, vol. 28, no. 3, pp. 1-4, 2005.

[36] W. Zhou, H. C. Deng, D. Z. Qiu, and R. C. Xie, “The discovery and significance of the Devonian paleo-reservoir in Tianjingshan structure of the northwest Sichuan, China.," Journal of Chengdu University of Technology (Science \& Technology Edition), vol. 34, no. 4, pp. 413-417, 2007.

[37] X. M. Sun, Q. W. Xu, Y. D. Wang, J. X. Tian, S. Q. Wang, and J. Y. Du, "Reservoir forming characteristics and main controlling factors of oil sandstones in the northern Longmen Mountain thurst zone of the northwest of Sichuan," Journal of Jilin University (Earth Science Edition), vol. 40, no. 4, pp. 886896, 2010.

[38] X. L. Shan, H. H. Luo, X. M. Sun, Y. Y. Zhang, and J. Yi, "Main factors of Houba Jurassic large oil sands reservior in Sichuan Basin," Journal of Jilin University (Earth Science Edition), vol. 40, no. 4, pp. 897-904, 2010.

[39] X. F. Yang, X. Z. Wang, S. N. Zhang et al., "Sedimentary characteristic and oilsands prediction in the upper Shaximiao formation, Houba area, northwestern Sichuan Basin," Geological Science and Technology Information, vol. 33, no. 3, pp. 112117, 2014.

[40] G. X. Liu, S. D. Wang, W. L. Pan, and J. X. Lv, "Characteristics of Tianjingshan destroyed oil reservoir in Guangyuan area, Sichuan," Marine Origin Petroleum Geology, vol. 8, no. 1, pp. 103-107, 2003.

[41] S. Y. Wang, Q. Ming, Z. Y. He, and L. Huang, "Study on forming process and geochemical character of the crude oil in fracture of the limestone in northwest of Sichuan," Journal of Natural Gas Geoscience, vol. 17, no. 4, pp. 579-581, 2006.

[42] H. M. Dai, W. L. Liu, Y. M. Yang, Y. G. Li, and Y. Duan, "The origin of Jurassic oil-soaked sandstone in the piedmont zone of north Longmenshan, the Sichuan Basin," Petroleum Geology \& Experiment, vol. 36, no. 6, pp. 604-608, 2007.

[43] D. Rao, J. Z. Qin, G. E. Teng, and M. Z. Zhang, "Source analysis of oil seepage and bitumen originating from marine layer strata in Guangyuan area, the northwest Sichuan Basin," Petroleum Geology \& Experiment, vol. 30, no. 6, pp. 596-605, 2008.

[44] D. F. Huang and L. S. Wang, "Geochemical characteristics of bituminous dike in Kuangshanliang area of the northwestern Sichuan Basin and its significance," Acta Petrolei Sinica, vol. 29, no. 1, pp. 23-28, 2008.

[45] C. Liu, H. L. Zhang, A. J. Shen, Z. F. Qiao, X. F. Ni, and X. X. Zhao, "Geochemistry characteristics and origin of the Devonian oil-sandstone in the northwest of Sichuan Basin," Acta Petrolei Sinica, vol. 31, no. 2, pp. 253-258, 2010.

[46] C. Liu, Q. X. Guo, and H. L. Zhang, "The discovery and geological significance of petroleum of Triassic Feixianguan 
Formation in northwest Sichuan Basin," Natural Gas Geoscience, vol. 22, no. 4, pp. 692-699, 2011.

[47] M. Luo, A. S. Geng, Z. W. Liao, and X. L. Shan, "The organic geochemical characteristics and genesis study of Houba oil sand in the Sichuan Basin, China," Geochimica, vol. 40, no. 3, pp. 280-288, 2011.

[48] L. L. Wu, Y. H. Liao, Y. X. Fang, and A. S. Geng, “The study on the source of the oil seeps and bitumens in the Tianjingshan structure of the northern Longmen Mountain structure of Sichuan Basin, China," Marine and Petroleum Geology, vol. 37, no. 1, pp. 147-161, 2012.

[49] G. L. Wang, T. G. Wang, K. Y. Han, and S. B. Shi, “Organic geochemical characteristics and origin of solid bitumen and oil sands in northwestern Sichuan," Petroleum Geology and Experiment, vol. 36, no. 6, pp. 731-735, 2014.

[50] C. B. Shen, S. David, L. F. Mei et al., "Advances in the study of Re-Os geochronology and tracing of hydrocarbon generation and accumulation," Journal of Mineralogy and Petrology, vol. 31, no. 4, pp. 87-93, 2011.

[51] J. Wang, L. Tenger, L. B. Ma et al., "Definition of petroleum generating time for Lower Cambrian bitumen of the Kuangshanliang in the west Sichuan Basin, China: evidence from Re-Os isotopic isochron age," Natural Gas Geoscience, vol. 27, no. 7, pp. 1290-1298, 2016.

[52] X. Ge, C. Shen, D. Selby et al., "Petroleum-generation timing and source in the northern Longmen Shan thrust belt, southwest China: implications for multiple oil-generation episodes and sources," AAPG Bulletin, vol. 102, no. 5, pp. 913-938, 2018.

[53] Z. C. Wang, J. J. Liu, H. Jiang et al., "Lithofacies paleogeography and exploration significance of Sinian Doushantuo depositional stage in the middle-upper Yangtze region, Sichuan Basin, SW China," Petroleum Exploration and Development, vol. 46, no. 1, pp. 39-51, 2019.

[54] G. D. Love, C. E. Snape, A. D. Carr, and R. C. Houghton, "Release of covalently-bound alkane biomarkers in high yields from kerogen via catalytic hydropyrolysis," Organic Geochemistry, vol. 23, no. 10, pp. 981-986, 1995.

[55] I. P. Murray, G. D. Love, C. E. Snape, and N. J. L. Bailey, "Comparison of covalently-bound aliphatic biomarkers released via hydropyrolysis with their solvent-extractable counterparts for a suite of Kimmeridge clays," Organic Geochemistry, vol. 29, no. 5-7, pp. 1487-1505, 1998.

[56] L. L. Wu, Y. H. Liao, Y. X. Fang, and A. S. Geng, "The comparison of biomarkers released by hydropyrolysis and by Soxhlet extraction from source rocks of different maturities," Chinese Science Bulletin, vol. 57, no. 32, pp. 3067-3077, 2012.

[57] Y. Liao, Y. Fang, L. Wu, A. Geng, and C. S. Hsu, "The characteristics of the biomarkers and $\delta^{13} \mathrm{C}$ of $n$-alkanes released from thermally altered solid bitumens at various maturities by catalytic hydropyrolysis," Organic Geochemistry, vol. 46, pp. 5665, 2012.

[58] G. Q. Wei, Z. H. Wang, J. Li, W. Yang, and Z. Y. Xie, "Characteristics of source rocks, resource potential and exploration direction of Sinian and Cambrian in Sichuan Basin," Journal of Natural Gas Geoscience, vol. 28, no. 1, pp. 1-13, 2017.

[59] K. Zhang, C. Jia, Y. Song et al., "Analysis of lower Cambrian shale gas composition, source and accumulation pattern in different tectonic backgrounds: a case study of Weiyuan block in the upper Yangtze region and Xiuwu Basin in the lower Yangtze region," Fuel, vol. 263, p. 115978, 2020.
[60] K. E. Peters, C. C. Walters, and J. M. Moldowan, The Biomarker Guide, Biomarkers and Isotopes in Petroleum Exploration and Earth History, Cambridge University Press, New York, 2005.

[61] W. K. Seifert, J. M. Moldowan, and G. J. Demaison, "Source correlation of biodegraded oils," Organic Geochemistry, vol. 6, pp. 633-643, 1984.

[62] W. K. Seifert and J. M. Moldowan, "Use of biological markers in petroleum exploration," in Methods in Geochemistry and Geophysics, R. B. Johns, Ed., pp. 261-290, Elsevier, New York, 1986.

[63] G. Ourisson, P. Albrecht, and M. Rohmer, "Predictive microbial biochemistry - from molecular fossils to procaryotic membranes," Organic Geochemistry, vol. 7, no. 7, pp. 236239, 1982.

[64] J. K. Volkman, M. R. Banks, K. Denwer, and F. R. Aquino Neto, "Biomarker composition and depositional setting tasmanite oil shale from northern Tasmania, Australia," 14th International Meeting on Organic Geochemistry, 1989, Paris, September 1989, 1989.

[65] F. R. A. Neto, J. Trigüis, D. A. Azevedo, R. Rodriques, and B. R. T. Simoneit, "Organic geochemistry of geographically unrelated tasmanites," Organic Geochemistry, vol. 18, no. 6, pp. 791-803, 1992.

[66] D. A. Azevedo, F. R. Aquino Neto, B. R. T. Simoneit, and A. C. Pinto, "Novel series of tricyclic aromatic terpanes characterized in Tasmanian tasmanite," Organic Geochemistry, vol. 18, no. 1, pp. 9-16, 1992.

[67] P. F. Greenwood, K. R. Arouri, and S. C. George, "Tricyclic terpenoid composition of tasmanites kerogen as determined by pyrolysis GC-MS," Geochimica et Cosmochimica Acta, vol. 64, no. 7, pp. 1249-1263, 2000.

[68] F. R. Aquino Neto, J. M. Trendel, A. Restle, J. Connan, and P. A. Albrecht, "Occurrence and formation of tricyclic and tetracyclic terpanes in sediments and petroleums," in Advances in Organic Geochemistry 1981, pp. 659-676, J. Wiley and Sons, New York, 1983.

[69] H. Tappan, The Pale Biology of Plant Protists, Freeman W H and Company, San Francisco, 1980.

[70] S. Dutta, P. F. Greenwood, R. Brocke, R. G. Schaefer, and U. Mann, "New insights into the relationship between tasmanites and tricyclic terpenoids," Organic Geochemistry, vol. 37, no. 1, pp. 117-127, 2006.

[71] J. Connan, A. Restle, and P. Albrecht, "Biodegradation of crude oil in the Aquitaine basin," Physics and Chemistry of the Earth, vol. 12, pp. 1-17, 1980.

[72] W. K. Seifert and J. M. Moldowan, "The effect of biodegradation on steranes and terpanes in crude oils," Geochimica et Cosmochimica Acta, vol. 43, no. 1, pp. 111-126, 1979.

[73] R. P. Philp and T. D. Gilbert, "Biomarker distributions in oils predominantly derived from terrigenous source material," in Advances in Organic Geochemistry 1985, D. Leythaeuser and R. Ötter, Eds., pp. 73-84, Pergamon Press, 1986.

[74] F. R. A. Neto, A. Restle, J. Connan, P. Albrecht, and G. Ourisson, "Novel tricyclic terpanes $\left(\mathrm{C}_{19}, \mathrm{C}_{20}\right)$ in sediments and petroleums," Tetrahedron Letters, vol. 23, no. 19, pp. 2027-2030, 1982.

[75] J. Connan, J. Bouroullec, D. Dessort, and P. Albrecht, "The microbial input in carbonate-anhydrite facies of a sabkha palaeoenvironment from Guatemala: a molecular approach," Organic Geochemistry, vol. 10, no. 1-3, pp. 29-50, 1986. 
[76] S. G. Liu, S. Liu, W. Sun et al., "Tectonic and sedimentary features of the northern Mianyang-Changning intracratonic sag, Sichuan, China," Journal of Chengdu University of Technology (Science \& Technology Edition), vol. 45, no. 1, pp. 113, 2018.

[77] Y. G. Wang, Y. C. Wen, H. T. Hong et al., "Petroleum geological characteristics of deep water deposits in Upper PermianLower Triassic trough in Sichuan basin and adjacent areas," Oil \& Gas Geology, vol. 27, no. 5, pp. 702-714, 2006.

[78] L. M. Wenger and G. H. Isaksen, "Control of hydrocarbon seepage intensity on level of biodegradation in sea bottom sediments," Organic Geochemistry, vol. 33, no. 12, pp. 1277-1292, 2002.

[79] J. W. De Leeuw and M. Bass, "Early diagenesis of steroids," in Biological Markers in the Sedimentary Record, R. B. Johns, Ed., pp. 102-127, Elsevier, Amsterdam, 1986.

[80] Y. Fang, Y. Liao, L. Wu, and A. Geng, "Oil-source correlation for the paleo-reservoir in the Majiang area and remnant reservoir in the Kaili area, south China," Journal of Asian Earth Sciences, vol. 41, no. 2, pp. 147-158, 2011.

[81] M. Bjorøy, K. Hall, P. Gillyon, and J. Jumeau, "Carbon isotope variations in $n$-alkanes and isoprenoids of whole oils," Chemical Geology, vol. 93, no. 1-2, pp. 13-20, 1991.

[82] D. R. Wang, Stable Isotope Geochemistry of Oil and Gas, Publishing House of Oil Industry, Beijing, 2000.

[83] W. J. Stahl, "Carbon and nitrogen isotopes in hydrocarbon research and exploration," Chemical Geology, vol. 20, pp. 121-149, 1977.

[84] Z. L. Luo, "The influence of Taphrogenesis from late Paleozoic Era in southern China on petroleum and other deposits," Sichuan Geologica Journal, vol. 2, no. 1, pp. 1-22, 1981.

[85] D. F. He and S. L. Wu, "The "past and present" of the Tianjingshan palaeo-uplift: discussion on structural restoration of paleo-uplift," Earth Science Frontiers, vol. 26, no. 1, pp. 86101, 2019.

[86] G. M. Zhai, Petroleum Geology of China: Vol. 10, Petroleum Industry Press, Beijing, 1989.

[87] W. H. Song, "Some new knowledge of Caledonian paleo-uplift in Sichuan Basin," Natural Gas Indusdry, vol. 9, no. 3, pp. 12$16,1987$.

[88] G. H. Li, G. Yang, L. Li et al., "Formation and evolution of Tianjingshan paleo-uplift, northwestern margin of Sichuan Basin," Natural Gas Exploration and Development, vol. 41, no. 4, pp. 1-7, 2019.

[89] K. F. Yu and S. D. Wang, "Duyun movement in South Guizhou Province and its paleostructure, and their significance in petroleum geology," Guizhou Geology, vol. 12, pp. 225-232, 1995.

[90] D. S. Sun, S. J. Li, D. Y. Zhu, D. W. Zhang, Y. J. Wo, and Z. L. $\mathrm{He}$, "Unconformity of the Duyun movement in the Sichuan Basin and its significance of petroleum geology," Oil \& Gas Geology, vol. 5, pp. 721-728, 2015.

[91] T. S. Zhang and F. H. Hou, "Reefs discovered in the lowermiddle Silurian, northwest Sichuan," Journal of Southwestern Petroleum Institute, vol. 2, pp. 139-140, 1989.

[92] D. Y. Liu, X. Chen, and T. R. Zhang, "Memoirs of Nanjing Institute of Geology and Palaeontology," Academia Sinica, Stratigraphy, vol. 1, pp. 161-170, 1964.

[93] S. Qin, T. Zhang, W. B. Su, W. Wang, and C. Ma, "Characteristics and implications of the oolitic limestones from the Silurian succession in Wangcang, Sichuan, South China," Earth
Science-Journal of China University of Geosciences, vol. 36, no. 1, pp. 43-52, 2011.

[94] W. J. Liu, R. C. Zheng, and X. H. Li, "Reconstruction of palaeogeography and palaeotectonics of a Devonian sedimentary basin in the Longmenshan area, Sichuan," Acta Geologica Sinica, vol. 73, no. 2, pp. 109-119, 1999.

[95] J. X. Qin, Y. F. Zeng, Z. X. Huang, and Y. Wu, “Carboniferous sequence stratigraphy and sea-level changes in the Majiaoba District, Sichuan," Sedimentary Facies and Palaeogeography, vol. 16, no. 1, pp. 19-33, 1996.

[96] S. G. Liu, C. Qin, W. Sun et al., “The coupling formation process of four centers of hydrocarbon in Sinian Dengying Formation of Sichuan Basin," Acta Petrologica Sinica, vol. 28, no. 3, pp. 879-888, 2012.

[97] S. G. Liu, W. Sun, J. M. Song et al., “Tectonics-controlled distribution of marine petroleum accumulations in the Sichuan Basin, China," Earth Science Frontiers, vol. 22, no. 3, pp. 146-160, 2015.

[98] X. Liang, S. G. Liu, S. B. Wang, B. Deng, S. Zhou, and W. Ma, "Analysis of the oldest carbonate gas reservoir in China-new geological significance of the Dengying gas reservoir in the Weiyuan Structure, Sichuan Basin," Journal of Earth Science, vol. 30, no. 2, pp. 348-366, 2019. 